\title{
Persistent Policy Pathways: Inferring Diffusion Networks in the American States*
}

\author{
Bruce A. Desmarais ${ }^{\dagger} \quad$ Jeffrey J. Harden ${ }^{\ddagger} \quad$ Frederick J. Boehmke ${ }^{\S}$
}

November 2, 2014

Forthcoming, American Political Science Review

\begin{abstract}
The transmission of ideas, information, and resources forms the core of many issues studied in political science, including collective action, cooperation, and development. While these processes imply dynamic connections among political actors, researchers often cannot observe such interdependence. One example is public policy diffusion, which has long been a focus of multiple subfields. In the American state politics context, diffusion is commonly conceptualized as a dyadic process whereby states adopt policies (in part) because other states have adopted them. This implies a policy diffusion network connecting the states. Using a dataset of 187 policies, we introduce and apply an algorithm that infers this network from persistent diffusion patterns. The results contribute to knowledge on state policy diffusion in several respects. Additionally, in introducing network inference to political science, we provide scholars across the discipline with a general framework for empirically recovering the latent and dynamic interdependence among political actors.
\end{abstract}

\footnotetext{
*Previous versions of this article were presented at the Political Networks and Causality Conference (May 2013, University of Chicago), State Politics and Policy Conference, (May 2013, University of Iowa), Political Networks Conference (June 2013, Indiana University), Political Methodology Conference (July 2013, University of Virginia), and New Frontiers in Policy Diffusion Conference (March 2014, University of Iowa). For helpful feedback, we thank Craig Volden, Chuck Shipan, Betsy Sinclair, Tom Carsey, Virginia Gray, Kristin Garrett, Josh Jansa, Brian Schaffner, Ray La Raja, Jesse Rhodes, Jan Box-Steffensmeier, Meg Shannon, Anand Sokhey, Scott Althaus, and the editors and anonymous reviewers at the APSR. Bruce A. Desmarais acknowledges support from the National Science Foundation (grants \#SES-1357606 and \#CISE-1320219).

${ }^{\dagger}$ Assistant Professor, Department of Political Science, University of Massachusetts-Amherst, 420 Thompson Hall, 200 Hicks Way, Amherst, MA 01003, desmarais@ polsci.umass.edu.

¥Assistant Professor, Department of Political Science, University of Colorado Boulder, 136 Ketchum, UCB 333, Boulder, CO 80309, jeffrey.harden@ colorado.edu.

${ }^{\S}$ Professor, Department of Political Science, and Director of the Social Science Program in the Public Policy Center, University of Iowa, 341 Schaeffer Hall, Iowa City, IA 52242, frederick-boehmke@ uiowa.edu.
} 


\section{Introduction}

A central feature of political science is the dynamic interdependence among political actors. Citizens, elites, governments, and countries all display intergroup connections because group members repeatedly face common sets of choices. Furthermore, the decisions made by one actor in a group often influence those of the others. As a result, many critical issues that political scientists study—such as collective action problems, international cooperation, and economic development - are influenced by the flow of ideas, information, and resources between those connected political actors. Yet while scholars are often able to observe the flow of information itself, empirically identifying the underlying network of connections-usually the concept of chief theoretical interest-is more difficult, especially if that network changes over time. In this research we introduce to the discipline a general method for inferring a dynamic network connecting political actors based only on observable information about the repeated choices that those actors make.

The methodology we introduce is applicable to a wide range of research areas across political science. However, to demonstrate its utility, we focus the bulk of our attention on one notable instance of this phenomenon: the diffusion of public policies across the American states. A considerable amount of scholarship documents how policies, norms, agreements, and even wars diffuse across political boundaries. Indeed, Graham, Shipan, and Volden (2013) identify more than 800 articles from the past 50 years on diffusion processes in American politics, comparative politics, and international relations. A central theme in all of this work is that peer governments are connected to one another by their repeated policy decisions. However, observing systematic patterns in those connections over time-who tends to lead and who tends to follow-is a difficult task. We provide a means of doing so here by inferring a policy diffusion network based on the adoption of many policies over time. Moreover, we demonstrate how and why this dynamic network is crucial to understanding the diffusion process.

In what follows we demonstrate the significance of policy diffusion network inference and analysis. We begin by grounding the concept of a diffusion network in the theoretical framework of diffusion studies. We highlight that several scholars have suggested the existence of a diffusion 
network in theory, but never had the means of empirically measuring the ties in the network. Then we describe our network inference methodology; recently developed in machine learning, it can be used to infer a latent diffusion network from data consisting of binary diffusion "cascades." Next we apply the algorithm to infer our network of state policy diffusion. Then we illustrate how including information from the inferred diffusion network as a covariate in well-known policy diffusion studies improves model fit. Following that, we present an analysis of the factors that predict the formation of diffusion ties between states. Finally, we close with a discussion of the broad applicability of our methodology to many different research areas in political science.

\section{Conceptualizing a Policy Diffusion Network}

The institution of federalism provides an ideal environment for diffusion processes by encouraging member governments to compete with or learn from one another. The American states represent an important example of such an environment (e.g., Walker 1969; Gray 1973; Berry and Berry 1990; Shipan and Volden 2012). Indeed, the states are connected in many ways, including shared history and culture, the exchange of goods, migration of citizens, and overlapping media markets. A key result of these connections is that states look to each other when making policy. Due to myriad competitive, cooperative, and imitative forces, policy innovations regularly spread throughout the American states, and scholars have worked for decades to develop theoretical and empirical tools to understand and evaluate the various forces that underlie diffusion episodes. This has proven to be a difficult task because it requires conceptual and empirical separation of policy adoption, in which a state passes a new law as a result of internal and/or external determinants, and policy diffusion, which specifically refers to the external influence that other states exert on adoption in the state.

The broad arc of the literature on policy diffusion has moved from an initial interest in looking for consistent patterns of diffusion between states across multiple policies to the application of new methodologies or measurement strategies to single-policy diffusion episodes and finally to a renewed interest in the general patterns across policies. This return of the pendulum to detecting persistent pathways of diffusion results from recent theoretical and methodological advancements 
that provide the impetus for reexamining the foundational questions posed at the outset.

In his pioneering study, Walker (1969) stated his primary goals as (1) determining whether a group of policy leaders existed and, if so, (2) how policies spread from these pioneering states to the rest of the American states. After his innovation scores provided an affirmative answer to the first question, he moved to developing a theoretical and empirical approach for determining the existence of "more or less stable patterns of diffusion of innovations among the American states" (Walker 1969, 888). He theorized that these patterns would reflect both geographic proximity and states' locations within various national communication channels formed by associations of state officials, organized interests, consultants, and academics. Given the limitations of the time, his empirical analysis focused on the presence of regional groupings. He found that while regional groupings existed, the evidence clearly pointed to additional influences that blurred these regional distinctions. ${ }^{1}$ While subsequent work by Gray (1973) offered a number of important critiques of Walker's (1969) approach, it continued to conceptualize diffusion as reflective of "regional or professional communication networks [that] may produce distinctive diffusion patterns" (1176).

While these critiques stunted the pursuit of comparing innovativeness across states, the literature continued to pursue the idea of evaluating patterns of policy diffusion. Event history analysis (EHA), introduced for the study of policy diffusion by Berry and Berry (1990) in their analysis of the diffusion of state lottery adoptions, has been the primary vehicle for this pursuit as it offers the opportunity to simultaneously account for time-varying internal and external determinants of policy adoption. It addresses many of the concerns raised by Gray (1973) and others about Walker's (1969) innovation scores and led to the development of a robust literature on policy adoption. During this era, researchers almost exclusively focused on one policy at a time since that fit within the EHA framework. Furthermore, while these researchers highlighted the role of a variety of internal determinants of adoption, the central external determinant of interest was geographic contiguity, which was meant to capture diffusion between neighboring states. Despite notable exceptions such

\footnotetext{
${ }^{1}$ More recent work also highlights diffusion between non-contiguous states. For example, California is considered both a prolific policy innovator in general (Volden 2006) and a leader in energy and environmental policy specifically (Ghanadan and Koomey 2005). New Jersey and Maryland have both recently implemented policies explicitly modeled after energy and emissions policies in California (Nussbaum 2007; Wagner 2007).
} 
as Mintrom and Vergari's (1998) study of policy entrepreneurs' connections across states or Grossback, Nicholson-Crotty, and Peterson's (2004) evaluation of ideological similarity with previous adopters, the vast majority of studies continued to examine only contiguity. A common finding in this work is that the probability of adoption increases as more of a state's neighbors adopt the policy (but see Mooney 2001).

After dominating the field for more than twenty years, single policy EHA studies began to run their course in terms of pushing the boundaries of knowledge. Researchers responded by moving in different directions, including a micro level approach that examines the internal legislative processes that influence policy adoption (Karch 2007) and studying how policy characteristics affect the overall rate of diffusion (Boushey 2010; Nicholson-Crotty 2009). Other researchers pushed forward on studying the patterns of interstate diffusion in creative ways: the incorporation of Geographic Information Systems (GIS) to develop more nuanced measures of economic diffusion pressures between contiguous states (Berry and Baybeck 2005), the consideration of policy adoption and expansion to separate the role of economic and social learning forces behind diffusion (Boehmke and Witmer 2004), and the examination of bottom-up or top-down diffusion between cities, states, and the Federal government (Shipan and Volden 2006).

One of the biggest innovations during this period was the development of the dyadic EHA approach by Volden (2006). The dyadic EHA eschews adoption as its outcome of interest and instead considers whether a policy change by a state moves it closer to the policies of other states. An increase in policy similarity between pairs of states serves as the dependent variable and the dyadic structure facilitates evaluating whether a state moves its policy closer to those of other states whose policy differs (Boehmke 2009). This allows the consideration of a variety of absolute and relative characteristics of state dyads, including contiguity, but also ideological similarity and policy success in states that might be emulated. This approach has been applied to health policy in the United States (Volden 2006) as well as to unemployment policy in OECD countries (Gilardi 2010).

Studies like these have prompted a new wave of theoretical arguments to explain patterns of 
diffusion, whether through competition between states (Baybeck, Berry, and Siegel 2011), learning and free-riding across states facing uncertainty about a policy's value (Volden, Ting, and Carpenter 2008), or through changes in public opinion resulting from constituent learning through policy choices in nearby states (Pacheco 2012). These theoretical advances have, in turn, resulted in new ways to examine diffusion empirically.

Despite the major strides these and other studies have taken to further our understanding of policy adoption, they have still done so in the context of a single policy. Even the dyadic EHA approach usually considers policy similarity based on multiple components of a single policy. So while the literature has made significant progress identifying the existence of diffusion pathways, we still know relatively little about their persistence. Put differently, almost no systematic progress has been made towards answering Walker's (1969) second question about general patterns of policy diffusion. While scholars have recently returned to the collection and analysis of large numbers of policies (Nicholson-Crotty 2009; Boushey 2010; Boehmke and Skinner 2012b), they have not yet used these databases to uncover persistent connections between states through public policy diffusion. Yet this approach seems to be most consistent with what Walker (1969), Gray (1973), and others had in mind at the founding of this literature.

Indeed, the patterns of policy diffusion between the American states serve as a perfect opportunity for identifying the presence and structure of a dynamic, latent, policy diffusion network. The structure of such a network has been one of the driving forces in the literature for half a century, yet methodological and data limitations placed critical restrictions on the ability of researchers to estimate and evaluate such a network more than one policy at a time. As we describe below, the recent combination of technical advances and accumulation of data on the timing of adoptions for scores of policies provides the information necessary to solve this problem.

To our knowledge the latent network that we estimate on these data provides the first empirical measure of the full state-to-state policy diffusion network. The intuition behind the meaning of this network, however, parallels that of the much-used contiguity network. Just as a state becomes more likely to adopt a policy when its neighboring states have previously done so, it should be 
more likely to adopt a policy when any state to which it is connected in its general diffusion network has already done so. After estimating this network, we therefore explore its structure in a number of ways. First, we identify leader states and compare the structure of the network to one specified solely by contiguity. Then we show that supplementing existing studies with information about prior adopters in this latent network improves our ability to predict the adoption of specific policies. We then investigate the structure of this network by evaluating the ability of theoretically important covariates to explain diffusion ties.

\section{Policy Diffusion Network Inference in the American States}

Gomez-Rodriguez, Leskovec, and Krause (2010) consider the problem of inferring latent diffusion pathways connecting units (e.g., states or countries) based on data recording the times at which those units adopted or were infected with some attribute (e.g., a policy), over several attributes. Two non-policy-adoption examples are data on when a collection of people fell ill over several ailments or data on when news websites reported a given story over several stories. These cascades, as they are termed, exhibit the footprint of a hidden diffusion network connecting the units under study. Information on policy adoption for several states or countries and several policies constitutes data of this type. Here we use Gomez-Rodriguez, Leskovec, and Krause's (2010) latent network inference algorithm, called Net In $f$, to infer policy diffusion networks connecting the American states over time.

The NetInf algorithm is derived and described in detail in the online appendix. Here we give a broad overview of its major steps. The inferential task is the identification of a latent, directed network (i.e., each tie has a sender and a receiver) that can be used to explain a dataset with several cascades, where each cascade is a recording of when units (e.g., states) exhibited some dichotomous attribute (e.g., a policy adoption). Each cascade is stylistically represented as a tree, in which there is a branch for each diffusion instance whereby the attribute (e.g., policy) spreads from the origin (i.e., sender) of the branch to the destination (i.e., receiver). The network being inferred constrains the trees that can be used to construct the cascade such that only edges in the network can be used to construct the trees. The network is tied to the set of cascades in that 
the algorithm will attempt to find edges that can be used in trees to explain many cascades. The structure of this algorithm actually fits quite closely with Walker's (1969) description of the ideal way to represent state-to-state policy diffusion:

At the top of the tree would be a set of pioneering states which would be linked together in a national system of emulation and competition. The rest of the states would be sorted out along branches of the tree according to the pioneer, or set of pioneers, from which they take their principal cues (Walker 1969, 893).

Here we apply Net Inf to a moving window of policy adoptions on the 187 policies included in the database introduced by Boehmke and Skinner (2012b) to infer an evolving state-to-state policy diffusion network for the years 1960-2009. ${ }^{2}$ Before presenting our application further, we define some useful terminology. We infer a different network in each year $(t)$. The diffusion ties (i.e., edges) that we infer are directed, identifying for each pair of states $(i, j)$, whether policies diffuse from $i$ to $j$, from $j$ to $i$, both, or neither. For a directed edge $i \rightarrow j$, which indicates that policies diffuse from $i$ to $j$, we refer to $i$ as the source and $j$ as a follower. Thus, if the edge $i \rightarrow j$ exists in the network at time $t$, then we say $i$ is a source of policy for the follower $j$ at time $t .^{3}$

\section{Net Inf Overview}

Now that the broad structure of the algorithm and components of our application have been described, we present a few critical details on how edges in the diffusion network are selected along with an illustrative example. Three main factors contribute to the likelihood that state $i$

\footnotetext{
${ }^{2}$ Several other data collection efforts, such as content analysis of legislative journals, model legislation, or public records, could also be used to infer the diffusion network (e.g., Garrett and Jansa 2013). The significant advantage we gain from Net Inf is the scale and scope of policy adoption data coverage; in this case, we simply need to know the years in which states adopted the policies. This allows us to infer the network at yearly intervals over a very long span of time and across many policies with minimal coding rules. Indeed, we contend that Net Inf can provide a great deal of information to political scientists across the discipline even with a relatively feasible data collection effort.

${ }^{3}$ As with most research on policy diffusion, we are limited by the fact that our data comprise only successful instances of the spread of policies. However, Net In $f$ could be extended to incorporate unsuccessful or never-attempted cases of diffusion because information on those cases - if it were available - could be put into the cascade data structure that Net Inf employs for inference. The main roadblocks to this are (1) defining what constitutes an unsuccessful attempt and (2) collecting data on those attempts over time. Research by Karch, Nicholson-Crotty, Woods, and Bowman (2013) begins to overcome these issues, but only for a specific set of policies that are implemented as interstate compacts. Nonetheless, as this research grows, Net Inf is well-positioned to be useful in understanding how policy diffusion networks affect successful and unsuccessful diffusion.
} 
will be identified as a source for $j$. Collectively, these factors ensure that Net In $f$ is picking up patterns consistent with the definition of policy diffusion given above, rather than just chance sequential adoption of the same policy by two states.

(1) The number of times $i$ adopts a policy before $j$. Net In $f$ uses edges it infers to explain the individual cascades, but an edge from $i$ to $j$ can only be used if $i$ adopts before $j$. The number of times $i$ adopts before $j$ represents a ceiling on the number of times Net In $f$ can use an edge from $i$ to $j$ in a cascade-specific tree.

(2) The length of time between $i$ 's adoptions and $j$ 's adoptions. The wait times are parameterized as exponentially distributed, which means short times are more likely than long times. Thus, Net Inf would prefer to use single edges to explain short times between adoptions, and chains of edges to explain longer times. The degree to which Net Inf prefers short to long times is governed by the tunable exponential rate parameter used in the algorithm.

(3) The precision with which an adoption by $i$ predicts an adoption by $j$. Net Inf uses a probability model in which adoption by sources is used to predict adoptions. If state $i$ simply adopts a lot of policies early, a result will be many $i$-then- $j$ sequences, but also many policies for which $i$ adopts and $j$ does not, which will penalize the probability model's likelihood with false positives.

Net Inf iteratively adds the edge that performs the best on the three factors above, weighted according to the underlying probability model (detailed in the online appendix). To smooth things out, the Net Inf probability model also includes a very low, but non-zero, probability that a state will adopt a policy when one of its sources has not previously adopted (i.e., the cascade can jump without an edge in the network). Another feature to note is that Net Inf prefers non-redundancy in forming the network. That is, if an edge has been added to the network that can be used to explain an adoption, Net Inf will prefer to add an edge that explains other adoptions that are not yet adequately explained by existing edges. 


\section{An Example: West Virginia, 1975-2009}

We illustrate the edge ranking and selection procedure using the case of identifying sources for West Virginia over the period 1975-2009. West Virginia adopted 39 policies over this time period. The first step in ranking and identifying potential sources for WV is to ask which states adopted several of those 39 policies prior to WV adopting. Among the other 49 states, the largest number of pre-WV adoptions we observe is 17. Colorado, California, and Connecticut all adopted 17 of the 39 policies adopted by WV before WV adopted them. This makes CO, CA, and CT strong potential sources for WV because each could be used to explain 17 of WV's policy adoptions. As it turns out, all three of the edges $\mathrm{CO} \rightarrow \mathrm{WV}, \mathrm{CT} \rightarrow \mathrm{WV}$, and $\mathrm{CA} \rightarrow \mathrm{WV}$ are added to the diffusion network that covers the period 1975-2009. The $\mathrm{CO} \rightarrow \mathrm{WV}$ edge is the $46^{\text {th }}$ (out of 300) added to the network for that period, the edge $\mathrm{CT} \rightarrow \mathrm{WV}$ is the $67^{\text {th }}$, and the edge $\mathrm{CA} \rightarrow \mathrm{WV}$ is the $112^{\text {th }}$. Note that the number of edges identified is a tunable parameter of Net In $f$, so if we had asked for only 100 or 50 edges, we would have excluded the $\mathrm{CA} \rightarrow \mathrm{WV}$ and the $\mathrm{CT} \rightarrow \mathrm{WV}$ edges, respectively. We also consider one more potential source state, Delaware, which adopted 16 policies prior to WV in this period, but is not identified as a source for WV.

In serving as potential sources for $\mathrm{WV}, \mathrm{CO}, \mathrm{CA}, \mathrm{CT}$, and $\mathrm{DE}$ are all high relative to other potential sources on the first point listed above: the number of $i$-then- $j$ sequences. The source quality ranking of $\mathrm{CO}>\mathrm{CT}>\mathrm{CA}>\mathrm{DE}$, results from their performance on the second two factors. Figure 1 depicts the distributions of years between the three potential source states and WV's adoptions for the policies in which the potential sources adopt before WV. The graph shows that WV adopted very shortly after CO in nearly all 17 instances. There were several longer lags for CT, more longer lags for DE, and many long lags for CA (e.g., 5-10 years). Thus, CO performs the best on criterion 2 (the length of time between $i$ 's and $j$ 's adoptions).

\section{[Insert Figure 1 here]}

Lastly, CO, CT, CA and DE adopted 57, 56, 68, and 53 policies, respectively, over the 19752009 period. These adoption frequencies factor in on the third criterion, the precision of an adop- 
tion by $i$ in predicting an adoption by $j$. Because CA adopted 18-20 percent more policies than $\mathrm{CO}, \mathrm{CT}$, or DE, policy adoption by $\mathrm{CA}$ is less effective at predicting an adoption by $\mathrm{WV}$ than are adoptions by $\mathrm{CO}$ or $\mathrm{CT}^{4}$

To understand why DE is not identified as a source, we need to dig a bit deeper into the comparative pre-WV adoption timing. Recall that Net Inf prefers to use edges to span short time periods in diffusion trees. In understanding how Net Inf chooses between potential sources, it is important to consider which potential source regularly adopts prior to the follower state, and relatively close to the follower state's adoption. Looking at WV's adoptions, we see that CO, CT, $\mathrm{CA}$, and DE were the most recent prior adopting states for $11,8,10$, and 3 policies, respectively. Because Net Inf prefers to use edges for short diffusion times, DE is not a good candidate source relative to other states.

\section{Network Inference over Time}

In order to represent variation in the network over time, we apply Net Inf to a moving window of policy adoptions. There are many ways we could divide the data in order to use Net Inf to infer a different network for each year. We base our approach on how the networks and measures computed on them would likely be used in future research. We expect, and later suggest, that scholars will use the diffusion networks in the same way they use geographic neighbors in statistical models of the adoption of new policies. That is, statistical models will use the number of state $s$ 's sources that have adopted the policy prior to $t$ to predict whether $s$ will adopt that policy at time $t$.

To avoid endogeneity in the use of the network at $t$ to predict adoption at $t$, we specify our time-varying network inference to assure that only policy adoptions prior to time $t$ are used to inform the structure of the diffusion network at time $t$. An edge from $i$ to $j$ at $t$ can be interpreted as indicating that the policy has frequently spread from $i$ to $j$ in the period immediately preceding

\footnotetext{
${ }^{4}$ To underscore their relative strength as sources for WV, we can consider the number of policies in which Net Inf uses each edge to explain adoptions out of the 17 instances in which each of the identified sources adopted a policy prior to $\mathrm{WV}$ adopting. The edges $\mathrm{CO} \rightarrow \mathrm{WV}, \mathrm{CT} \rightarrow \mathrm{WV}$, and $\mathrm{CA} \rightarrow \mathrm{WV}$ are used in 17, 10, and 9 policy cascades, respectively.
} 
$t$. This way, we can be certain that a state's policy adoption at time $t$ is not used, via the inferred network, to predict that same policy adoption at time $t .^{5}$

\section{Tuning Net Inf}

We set three parameters in the network inference procedure. First, we need to define the number of preceding years of adoptions that will be used to infer the network for time $t$. Second, we need to define the number of edges we want to infer. Third, we need to tune the rate parameter of the exponential distribution used by Net In $f$ to calibrate how long it takes for policies to diffuse from one state to another. The exponential distribution gives the distribution of diffusion times between states, provided that there is an edge connecting them. Higher rates place a higher penalty on the addition of edges to the network along which it takes a long time for policies to diffuse.

The procedure we use to select the values of these three parameters is fully described and illustrated in the online appendix. To give an overview, we use a grid search on a range of the number of edges from 100-1,000, the time interval from 5-50 years and the exponential rate parameter from 0.125-1 (i.e., an average diffusion time of 1-8 years). We infer a new time series of networks for each combination of tuning parameter values and evaluate the fit of an event history model, which does not include any other state covariates, in which we use the inferred networks to predict policy adoptions. Our process of tuning Net Inf represents a combination of theoretical and data-driven considerations. We rely upon prior theoretical expectations regarding the appropriate ranges in which we expect to find the optimal parameter values. We use a data-driven approach to identify the best set of parameters within these ranges. The only condition under which we would explore a broader range of the parameters is if we found a boundary solution in the grid search (e.g., if the best rate parameter were 0.125 , corresponding to an 8 year average diffusion time). ${ }^{6}$

\footnotetext{
${ }^{5}$ There may be concern that we infer one diffusion network at each time point, which models the diffusion of all policy adoptions within the respective time window. Indeed, some types of policies may diffuse in systematically different patterns than do other types of policies. In the online appendix we present diagnostics to evaluate whether there exist multiple classes of policies that systematically affect the ties inferred in the diffusion networks. We find very strong evidence that there are not multiple classes of diffusion patterns in our dataset of policies.

${ }^{6}$ Note that future researchers might choose to fix one or more of these parameters based on theory in order to focus on certain types of edges (e.g., fixing a high rate parameter to focus on fast diffusion or a small time interval to focus on short-term and volatile relationships).
} 
The networks that we use in the analysis that follows are those that result in the best fit over the grid of tuning parameter values. The network that results in the best predictive fit across all parameters is one with 300 edges and defined over 35 years of policy adoptions. Because we evaluate the tuning parameters, including the time interval, based on the effectiveness of the inferred ties in predicting future adoption cascades, we are not surprised to find that the bestperforming time interval is relatively long. Ties identified in relatively long time intervals will be those that are robust to historical fluctuations in political, social and economic conditions. ${ }^{7}$ The fit is not particularly sensitive to the rate parameter, but the network using a rate of 0.5 results in the best fit. This value corresponds to diffusion episodes that take, on average, two years. An average of approximately 1,900 adoption instances over an average of approximately 120 policies is used to infer the network for each year (precise distributions of these quantities are provided in the online appendix).

\section{Descriptive Analysis of the Policy Diffusion Network}

In this section we conduct descriptive and exploratory analyses of the network we have inferred. First, we demonstrate that the network is quite distinct from a set of relations recording geographic contiguity. Second, we summarize the outgoing and incoming diffusion ties of each state over five-year periods. Third, we provide an external empirical validation of the network by comparing it to newspaper reports of state-to-state emulation during the same time period.

\section{Geographic Contiguity}

The first descriptive feature of the diffusion network that we consider is its similarity to a network of geographic contiguity relations among states. Figure 2 plots the percentage of contiguity relations between states that are identified as diffusion ties (black line) and the percentage of inferred diffusion ties that are between contiguous states (gray line). Both of these percentages hover between ten and twenty percent between 1960 and 2009. This indicates that the overwhelming majority of policy diffusion relations exist between states that are not geographically contiguous.

\footnotetext{
${ }^{7} \mathrm{We}$ also use a network based on 400 edges and 10-year periods for use in two applications to policy diffusion models because that network fits those data best (see the online appendix).
} 
Therefore, although geographic contiguity represents a good first start, ties between neighboring states are not a comprehensive proxy for the policy diffusion network.

[Insert Figure 2 here]

\section{State-Level Activity in Diffusion Pathways}

Ranking states based on their innovativeness is a research problem that dates back at least to Walker (1969). Table 1 presents the top 15 states based on the number of states to which they send diffusion ties over five-year periods. In their time-aggregated measures of policy innovativeness, Walker (1969) and Boehmke and Skinner (2012b) find $\{\mathrm{CA}, \mathrm{NJ}, \mathrm{OR}, \mathrm{NY}, \mathrm{CT}\}$ and $\{\mathrm{CA}, \mathrm{NJ}, \mathrm{IL}$, NY, OR $\}$ to be the top five states, respectively. Many of these states are at the top of our list in each five year period. Only Florida emerges as an outlier with respect to previous rankings: Walker (1969) and Boehmke and Skinner (2012b) rank Florida as $13^{\text {th }}$ and $12^{\text {th }}$, respectively, whereas we find Florida to be in the top five for nearly every five year period, and at the top of the list for a decade.

\section{[Insert Table 1 here]}

To venture an explanation as to why Florida emerges as an innovator in our analysis, but not in previous studies, we present Table 2, which details how often each of the three top innovators (New York, California, and Florida) were first adopters, and also how often the other two did not adopt. We see from this table that, even though Florida is the least frequent first adopter among the three, the policies for which it is the first adopter are, at a very high rate, never adopted by New York or California. Thus, although Florida does not stand out as a notably frequent first adopter, it is often placed at the root of cascade trees because other frequent adopters are not innovators in policy areas led by Florida. This inference regarding Florida highlights a primary strength of NetInf: a state will not be deemed innovative based solely on the speed with which it adopts policies. Rather, a state is deemed innovative if its adoption serves to explain adoptions by other states that cannot be explained with reference to other early adopters.

[Insert Table 2 here] 


\section{Media-based Validation of the Policy Diffusion Network}

We have not yet connected the diffusion ties we have inferred with any real-world instances of state-to-state policy emulation. Given the high profile status of several areas in state law, selected major policy decisions at the state level are afforded in-depth press coverage (Tan and Weaver 2009). As we show below, newspaper articles often indicate when a substantial portion of a state law has been modeled after another state's policy. We identified accounts of policy emulation in journalistic coverage of state policymaking by searching LexisNexis Academic for newspaper articles containing the phrase, "modeled after a/an ***", where "***" was the name of a state, for all fifty states. ${ }^{8}$ LexisNexis covers newspaper articles going back to 1981 . We then counted of the number of stories that report the emulation of each states' policies. These documented instances of policy emulation can serve as the basis for a qualitative validation of the inferred network. If the news media accurately reports some (possibly biased) sample of actual policy emulation instances, then we should observe a positive association between the number of diffusion ties sent by a state and the number of media reports of that state being emulated by others.

Figure 3 depicts the bivariate relationship between the number of emulation stories identified and the average number of ties sent by each state in the inferred diffusion network, averaged over 1981-2009. On the linear scale, we find a strong correlation of $r=0.72$. However, two outliers-New York and California—have approximately twice as many emulation stories as any other state, so we also consider the correlation on the log-scale, which produces a slightly more moderate correlation of 0.621 . Both the Pearson's correlation coefficient and Spearman's rankbased correlation are statistically significant at the 0.01 level. ${ }^{9}$ The positive relationship between emulation reports in the media and average ties sent in the inferred diffusion network indicates that the diffusion relationships we identify align with in-depth journalistic accounts of state-to-state

\footnotetext{
${ }^{8}$ To avoid primarily nationally-oriented coverage, we excluded The New York Times, The Washington Post, USA Today and The Los Angeles Times from this analysis (but results are not contingent on this choice).

${ }^{9}$ Our online appendix describes a regression analysis in which we estimate the effect of inferred diffusion network ties on the number of emulation stories reported, adjusting for the total coverage of a state in LexisNexis. There is a strong positive and statistically significant relationship between emulation stories and diffusion ties after adjusting for total state news coverage.
} 
policy diffusion.

[Insert Figure 3 here]

\section{Applying the Inferred Network to Models of Policy Diffusion}

Most policy diffusion studies examine the influence of state-level features on the adoption of new policies as well as the influence states have on one another, primarily via contiguity. Our network of policy diffusion across the fifty states provides a novel opportunity to account for cross-state dependencies in these studies. To that end, we incorporated the inferred policy diffusion network into EHA models of diffusion for four separate policies: lotteries (Berry and Berry 1990), Indian gaming (Boehmke 2005), capital punishment (Boehmke 2005), and restaurant smoking bans (Shipan and Volden 2006). In addition to these policy-specific EHA models, we also replicated Boehmke and Skinner's (2012a) "pooled event history analysis" (PEHA) model fit to data on 151 different policies diffusing over the period 1960-1999 (see also Boehmke 2009).

To conserve space, we present the details of these applications of the inferred diffusion network in the online appendix. Briefly, they yield two primary contributions to research on state policy diffusion. First, they illustrate how the diffusion network can be integrated as a covariate in conventional diffusion models. We demonstrate that doing so produces statistically and substantively significant estimates of the effect of network ties on adoption and improves model fit. The second contribution stems from the fact that Net In $\mathrm{f}$ does not condition on covariates, making it possible that the ties inferred by Net $\operatorname{In} f$ arise from some underlying covariates that induce regular patterns of policy diffusion. Our replications show that the inferred ties are not simply an artifact of the covariates already known to influence policy adoption; rather, our diffusion network is a uniquely important aspect of the diffusion process. ${ }^{10}$

\footnotetext{
${ }^{10}$ We validated this characteristic of Net In $f$ with a simulation experiment in which we generated policy adoption data based solely on state covariates. Net Inf produced network estimates that were consistent with patterns in covariate values, which indicates that consistent effects of covariates can give the appearance of diffusion ties between states.
} 


\section{Understanding the Inferred Network}

Similar to other forms of latent variable (e.g., estimated legislator ideal points), the diffusion network we have identified likely arises from a complex combination of states' attributes and their relationships to each other, drawing from political, economic, and geographic factors. In our final analysis, we evaluate the structure of our inferred network through the lens of extant theoretical expectations about the identities of leaders and followers. We do so via multilevel logit models of source-follower ties over the period 1960-2009.

\section{Theoretical Framework}

The concepts of exploration and exploitation, referring to the processes of individual independent innovation and interactive emulation, respectively (Lazer and Friedman 2007), lie at the heart of social theories of problem solving and behavioral choice (see, e.g., Akers, Krohn, LanzaKaduce, and Radosevich 1979; Rice, Grant, Schmitz, and Torobin 1990; Kirke 2004; Berkes 2009). Sometimes referred to as social learning (Ellison and Fudenberg 1995; Hummon 2000), a growing body of research addresses how networks will and should be organized to cope with uncertainty regarding optimal decisions (Mason and Watts 2012). The theoretical framework of policy diffusion in the American states bears a strong resemblance to the general literature on learning in networks. Indeed, incomplete information underpins Walker's (1969) theory of policy diffusion and much of the subsequent research (e.g., May 1992; Mooney 2001; Volden 2006). States do not have the time or resources to fully evaluate all possible solutions to their pressing policy problems. Walker and others therefore suggest that states may act according to Simon's (1976) concept of satisficing, in which they attempt to identify policies that will improve their lot even if they may not constitute the optimal policy. To accomplish this, states rely on a set of heuristics to identify policies for possible adoption. Most importantly, states will look to the actions of other states as a source of information. These may be neighboring states, states with similar characteristics and therefore similar policy needs, or states with more extensive resources that act as leaders by investigating new policies. 
We draw our explanatory variables intended to capture states' capacity to innovate and learn from other states from among those commonly used in the literature. For example, Walker (1969) argues that more populous, wealthier states typically have the resources and motivation to learn about policies on their own and scholars using EHA have continued to include these variables. We also consider legislative professionalism, which diffusion scholars have more recently used as a measure of legislative capacity (see, e.g., Shipan and Volden 2006). Because previous EHA studies overwhelmingly focus on monadic policy diffusion, scholars typically use these variables to test whether greater resources lead states to adopt new polices faster. Because we seek to explain their effect on the diffusion network, however, we have the opportunity to separate their distinct effects on leaders and followers. If diffusion occurs according to an informational process, then states with greater capacity will tend to be leaders since they can investigate policies on their own more thoroughly. This also suggests that states with greater resources can also process more information and consider policy solutions in more states simultaneously. We therefore expect that states with greater resources are more likely to be sources, but also to identify other states as sources.

Beyond resource effects, however, we also want to capture Walker's idea of peer states. When identifying sources, states may look beyond the wealthiest states to states that have similar characteristics and whose choices may reflect more upon their specific circumstances. The process according to which similar nodes are more likely to form ties in a network is referred to as homophily, and is one of the most common effects found in research on social networks (Fowler, Heaney, Nickerson, Padgett, and Sinclair 2011). The identity of peer states likely goes beyond measures of capacity or expertise, however, so we also consider the role of factors for which similarity may matter in and of itself. In particular, we consider similarity in terms of ideology and racial diversity. Ideology plays a crucial role in the types of policies states seek to adopt. With incomplete information, then, states may look to the policies adopted by ideologically similar states rather than to those of dissimilar states since the former has a greater chance of providing a solution consistent with the preferences of its citizens. A number of studies have demonstrated that ideology influences whether a state will copy the policy adopted by another state (e.g., Grossback, 
Nicholson-Crotty, and Peterson 2004; Volden 2006; Volden, Ting, and Carpenter 2008). We also consider the role of racial and ethnic diversity. States with more heterogeneous populations face distinct policy challenges so we expect that states will use diversity in defining their peer network.

The most studied concept of peer states is geographic proximity. While Walker (1969) focused largely on regional clusters of states with a small number of their members serving as leaders, more developed theories have emerged over the years. Many focus on the role of contiguity explicitly, whether as a source of information transmission about public opinion (Boehmke 2005; Pacheco 2012) or as a facilitator of cross-border economic activity (Berry and Baybeck 2005; Baybeck, Berry, and Siegel 2011). While contiguity remains the workhorse variable for interstate diffusion, we also want to leverage the fact that our network considers the relationship between all pairs of states to examine the role of geographic proximity above and beyond contiguity. To do this we include a measure of distance between state capitals to test whether states have a regional tendency when determining their peers.

\section{Modeling Strategy}

In order to test for the effects of capacity and homophily on the leader-follower relationship, we include variables corresponding to each and enter them into our model in three ways. We start with variables on total state population and income from the Bureau of Economic Affairs, legislative professionalism (King 2000), Berry, Ringquist, Fording, and Hanson's (1998) citizen ideology (the revised 1960-2010 series), partisan control of state government (Klarner 2003), and racial diversity using Hero and Tolbert's (1996) formula applied to Census data. For each variable, we include its value in the potential source state to model which states tend to be emulated, its value in the potential follower state to capture the tendency of states to identify sources, and as a relative measure using their absolute difference (for continuous variables) or product (for the partisan control) to assess homophily. We expect that the measures of capacity have positive effects; that the relative measures of ideology and diversity exert negative effects (since larger values correspond to greater difference between the two states); and that shared borders and geographic proximity have positive effects. Of course, homophily likely extends beyond ideology and diversity, so we 
also expect that the absolute difference between these variables has a negative effect. We have no specific expectation about the role of ideology on its own in the source or follower state.

In order to evaluate these predictions, we estimate a multilevel, over-time, logit model of the diffusion network. ${ }^{11}$ In accordance with the structure of this network, each observation corresponds to whether one state considers a second state as a source. We therefore have dyadic data, which facilitates the inclusion of characteristics of each state separately as well as their relative characteristics. In order to account for dependence between observations we include two (nonnested) random effects: one for each state when it is the follower, choosing its peer network, and another when it is a potential source for other states. We also include, but do not report, a set of fixed effects for each year. ${ }^{12}$ Finally, recall that as we noted in the previous section the Net Inf algorithm does not condition on underlying covariates. As such, anything that would predispose two states to prefer the same policies might induce the appearance of diffusion ties among them. Measures of partisanship and political ideology would be chief among these common exposures when it comes to policymaking, which suggests some initial caution in interpreting these results.

\section{Results}

We report the results of this estimation in Table 3. Overall, they indicate the importance of capacity, political homophily, and geographic proximity. The results for capacity stand out as especially strong, with more populous states more likely to serve as sources and to identify other states as sources and larger and wealthier states to identify other states as sources. Further, we find strong evidence of homophily, with larger absolute differences between states decreasing the probability

\footnotetext{
${ }^{11}$ At this point we emphasize how our analysis departs from Volden's (2006) approach, because of important overlaps. The dependent variable that Volden (2006) uses is whether a state $A$ moves policy in the direction of state $B$ 's policy at time $t$, for all combinations of $A, B$, and $t$. This approach identifies policy specific emulation of $B$ by $A$. Of course, if several states have the same policy as $B$, Volden's approach cannot determine which state $A$ is emulating. In contrast, Net Inf searches for a network of edges that represent regular diffusion pathways over many policies, meaning that our approach is capable of identifying the state(s) that $A$ persistently emulates. However, our approach is not capable of identifying policy-specific diffusion ties between states - only ties that manifest consistently over many policies.

${ }^{12}$ Network data may exhibit more complex dependencies than directed vertex random effects (Cranmer and Desmarais 2011). As such, we used quadratic assignment procedure (QAP, see Krackardt 1987) - a permutation testing method designed for network data-to replicate the hypothesis tests presented in Table 3. The QAP was run for 500 iterations. We use the variant of QAP in which the rows and columns of the adjacency-matrix-valued dependent variable are permuted.
} 
of each state choosing the other as a source. Interestingly, though, legislative professionalism does not conform to this pattern. The effects for sources and followers are not statistically significant and the difference term has a positive effect—indicating heterophily—which is only significant according to the parametric $p$-values, indicating that states rely more on states with different values of professionalism.

\section{[Insert Table 3 here]}

Citizen ideology also produces results consistent with expectations. In particular, ideological distance has a negative and significant effect, demonstrating strong ideological homophily in diffusion. We also find that more liberal states have fewer sources and serve as sources less often. Analogous results obtain based on government control: unified Democratic states identify similar states as sources more often than states with divided government, but the effect is only statistically significant according to the parametric $p$-values. No effects emerge among unified Republican states.

In order to substantively interpret these coefficient estimates, we present a series of graphs that translates them into expected probabilities of source-follower ties. We first examine the homophily effects in Figure 4. To calculate these probabilities we set every continuous variable at its mean value and every dichotomous variable at its modal value in 1985 . We set the estimated random effects at their mean of zero. We then present partial effects for each set of variables: one changing just the value in the state seeking sources, one changing the value in potential sources, and one changing the absolute difference between them.

\section{[Insert Figure 4 here]}

Consider first the top left graph for the effects of ideology. The baseline condition involves citizen ideology at its mean value, represented by the vertical line. Moving ideology in a potential follower decreases the probability of identifying sources when the state becomes more liberal and increases it when the state becomes more conservative. A similar result occurs for the ideology of potential source states: more liberal states get chosen less often and more conservative states 
more often. Of course, both of these manipulations also increase ideological distance, which has a negative effect on source selection. The combined effect of making the potential source more liberal leads to an even greater decrease than either alone whereas making it more conservative leads to a less severe decrease. In terms of magnitude, the effects range from zero to about $30 \%$ relative to the baseline probability of about $15 \%$.

The other graphs show similar patterns for per capita income, population, and minority diversity. The magnitudes do differ quite a bit, with population showing very large effects for a handful of large states and diversity producing a relatively small effect (note that the scales of the graphs differ to enhance readability). Interestingly, across all five plots, the follower state effect generally appears largest in magnitude, the homophily effect typically lies in the middle, and the potential source state effect is the smallest. Consistent with the individual coefficients, the results for legislative professionalism do not fit our expectations. While generally insignificant and small in magnitude, we find these results puzzling and hope to explore them in future work. One possible explanation rests in the high correlation of professionalism with population ( 0.72 in our sample).

We present the results for the other variables in Figure 5. Unified government control has a small effect, generally less than one or two percentage points. The biggest effects occur for same unified governments, with Democratic states most likely to choose other Democratic states as sources, but Republican states less likely to choose other Republican states. The bottom graph shows the effect of geographic distance and contiguity. Increasing distance by a thousand miles leads to an approximately two and a half percentage point drop in the probability of choosing a state as a source whereas contiguity leads to a minuscule change once we account for distancethe small capped bar at the minimum of 40 miles represents the estimated additional effect of contiguity.

[Insert Figure 5 here] 


\section{Network Inference in Political Science}

This research makes several substantive contributions to the literature on public policy diffusion in the American states. However, the network inference methodology is sufficiently general that it has the potential to impact several other research areas in political science. The obvious domain in which Net Inf is applicable is the literature on policy diffusion at the national level. Graham, Shipan, and Volden (2013) report that from 1958-2008, major political science journals published 307 policy diffusion articles in comparative politics and 226 in international relations (as well as 189 in American politics). However, political scientists also study many other phenomena that are comprised of a fixed set of actors (e.g., citizens, legislators, countries) who make repeated sequential decisions. Net In $f$ would be fruitfully applied in these domains to infer the connections between these actors.

Consider the study of international agreements and organizations. Shared affiliations in these institutions have been used as a proxy for ties between countries (e.g., Dorussen and Ward 2008). This measure has drawn criticism due to the largely static nature of membership in these institutions. As Hafner-Burton, Kahler, and Montgomery (2009) point out, "[a]lthough mutual membership in international institutions may lead to more opportunities for mutual interaction... it does not necessarily lead to positive ties, as is often assumed in international relations.... [M]embership may offer a static view of world politics" (578-579). Net Inf could solve this problem by constructing a dynamic network based on countries' repeated decisions to join intergovernmental organizations, trade agreements, and/or other international institutions (i.e., the cascades through which affiliations spread across countries).

Another possible use for Net Inf is to infer connections among legislators. In American politics, a long tradition of work examines legislative "cue-taking," or the process by which legislators look to other members in making voting and cosponsorship decisions (e.g., Kingdon 1973; Matthews and Stimson 1975). Network analysis has recently been employed to study legislators' interactions in the American (Tam Cho and Fowler 2010) and cross-national (Ringe, Victor, and Gross 2013) contexts. However, a common means of understanding how cue-taking oper- 
ates is through the use of legislator characteristics as covariates in regression models (e.g., BoxSteffensmeier, Arnold, and Zorn 1997). This is a useful approach, but due to the lack of a tie measurement method, it necessarily conflates sequence with cue-taking. Net Inf could solve this problem. Indeed, Net Inf has recently been applied to data on cosponsorship in the U.S. Senate with the aim of identifying the Senate influence network (Denny 2014).

Finally, political scientists and communication scholars are interested in intermedia agenda setting, or how media outlets interact through picking up stories from one another (e.g., Golan 2006; Denham 2014). Net Inf has the potential to infer a network of media outlet influence, which could be useful for studies that examine the media's impact on public attention to issues. Specifically, it could help scholars understand which outlets, news mediums, or people are most influential in setting the news agenda (e.g., Neuman, Guggenheim, Jang, and Bae 2014). In fact, the example that Gomez-Rodriguez, Leskovec, and Krause (2010) use to introduce Net In $f$ is the cascading of news articles among online media outlets over a one-year period.

Network inference has the potential to impact many areas across political science. Many important political phenomena are driven by patterns of influence and emulation. Thus, political science routinely confronts the fact that the individual decisions of a collection of actors affect, and are affected by, other actors. Net In $f$ is a useful means of dynamically measuring these relationships.

\section{Conclusions}

A half-century of research has examined the causes and consequences of policies diffusing across national and subnational boundaries. However, until now scholars have not had an ideal means of measuring the precise patterns though which policies diffuse. Geographic contiguity is one important factor, but does not capture the complete network of policy diffusion. In this research, we introduce a network inference methodology to political science and use it to infer a policy diffusion network connecting the American states.

We offer three broad contributions to the state politics literature. First, in contrast to common assumptions in research on state policy diffusion, we find that the overwhelming majority of diffusion ties connects states that are not geographic neighbors. Second, we show that the policy 
diffusion network we infer can improve explanatory models of policy adoption within specific policy areas. Our replications of previously published diffusion models indicate that when sources in a state's policy diffusion network adopt a policy, the likelihood of adoption significantly increases by a comparable amount to adoption by contiguous neighbors. Third, we present empirical models of the ties in the inferred networks to evaluate a number of theoretical perspectives on diffusion. Perhaps most interestingly, the results highlight the role of internal capacity and pairwise similarity, which tend to dominate. States with greater resources tend to have more peers, but all states favor other states that share similar demographic and political features. We also find evidence of leadership, with larger and wealthier states more often chosen as sources. While we have focused on extant theories, we hope that the availability of our estimates and future applications of Net In $f$ provide the impetus to test existing and develop new theories of interstate policy diffusion.

The current research opens the door to several future directions in methodology and state policy diffusion research. First, and chief among them, is extending the Net In $f$ algorithm to simultaneously infer covariate-based commonalities in policy adoptions as well as the underlying diffusion network. This would present the opportunity to precisely differentiate between diffusion ties and patterns that are attributable to covariates. A second worthwhile extension of Net Inf would be to incorporate whether policy innovations succeed or fail by some metric, which would allow us to evaluate the degree to which diffusion depends upon the result of the innovation. Third, our tracing of diffusion accounts in LexisNexis is rather limited, but demonstrates the feasibility of defining diffusion networks through the analysis of textual sources. Finally, though our work utilizes what is, to our knowledge, the most comprehensive database of state policy adoptions currently available, there are many more policies that could be traced through the states. An expanded policy database would permit fine-grained inference of policy-specific diffusion networks connecting the states and the chance to identify different structures by policy type.

A final contribution of this research is the introduction of the Net Inf technology to political science. While we illustrate its applicability in the context of state policy diffusion, it has broad potential for research in American politics, comparative politics, and international relations. The 
discipline often studies political actors who repeatedly face the same choices and make them in sequence. This means that interdependence between actors and the emergence of leaders and followers are likely to influence the processes under study. Net Inf helps to empirically recover this interdependence so that researchers can better understand its causes and consequences. 


\section{References}

Akers, Ronald L., Marvin D. Krohn, Lonn Lanza-Kaduce, and Marcia Radosevich. 1979. "Social Learning and Deviant Behavior: A Specific Test of a General Theory." American Sociological Review 44(4): 636-655.

Baybeck, Brady, William D. Berry, and David A. Siegel. 2011. "A Strategic Theory of Policy Diffusion Via Intergovernmental Competition.” Journal of Politics 73(1): 232-247.

Berkes, Fikret. 2009. "Evolution of Co-management: Role of Knowledge Generation, Bridging Organizations and Social Learning." Journal of Environmental Management 90(5): 1692-1702.

Berry, Frances Stokes, and William D. Berry. 1990. "State Lottery Adoptions as Policy Innovations: An Event History Analysis." American Political Science Review 84(2): 395-415.

Berry, William D., and Brady Baybeck. 2005. "Using Geographic Information Systems to Study Interstate Competition." American Political Science Review 99(4): 505-519.

Berry, William D., Evan J. Ringquist, Richard C. Fording, and Russell L. Hanson. 1998. "Measuring Citizen and Government Ideology in the American States, 1960-93." American Journal of Political Science 42(1): 327-348.

Boehmke, Frederick J. 2005. The Indirect Effect of Direct Legislation: How Institutions Shape Interest Group Systems. Columbus, OH: The Ohio State University Press.

Boehmke, Frederick J. 2009. "Policy Emulation or Policy Convergence? Potential Ambiguities in the Dyadic Event History Approach to State Policy Emulation.” Journal of Politics 71(3): 1125-1140.

Boehmke, Frederick J., and Paul Skinner. 2012a. "The Determinants of State Policy Innovativeness." Presented at the Annual State Politics and Policy Conference, Houston, TX.

Boehmke, Frederick J., and Paul Skinner. 2012b. "State Policy Innovativeness Revisited." State Politics \& Policy Quarterly 12(3): 303-329.

Boehmke, Frederick J, and Richard Witmer. 2004. "Disentangling Diffusion: The Effects of Social Learning and Economic Competition on State Policy Innovation and Expansion." Political Research Quarterly 57(1): 39-51.

Boushey, Graeme. 2010. Policy Diffusion Dynamics in America. New York: Cambridge University Press.

Box-Steffensmeier, Janet M., Laura W. Arnold, and Christopher J. W. Zorn. 1997. "The Strategic Timing of Position Taking in Congress: A Study of the North American Free Trade Agreement." American Political Science Review 91(2): 324-338.

Cranmer, Skyler J., and Bruce A. Desmarais. 2011. "Inferential Network Analysis with Exponential Random Graph Models." Political Analysis 19(1): 66-86.

Denham, Bryan E. 2014. "Intermedia Attribute Agenda Setting in the New York Times: The Case of Animal Abuse in U.S. Horse Racing." Journalism \& Mass Communication Quarterly 91(1): 17-37.

Denny, Matthew J. 2014. "Influence in the United States Senate." Presented at the Annual Meeting of the Midwest Political Science Association, Chicago, IL.

Dorussen, Han, and Hugh Ward. 2008. "Intergovernmental Organizations and the Kantian Peace: A Network Perspective.” Journal of Conflict Resolution 52(2): 189-212.

Ellison, Glenn, and Drew Fudenberg. 1995. "Word-of-Mouth Communication and Social Learning." Quarterly Journal of Economics 110(1): 93-125. 
Fowler, James H., Michael T. Heaney, David W. Nickerson, John F. Padgett, and Betsy Sinclair. 2011. "Causality in Political Networks." American Politics Research 39(2): 437-480.

Garrett, Kristin N., and Joshua M. Jansa. 2013. "Interest Group Influence in Policy Diffusion Networks." Presented at the Annual Meeting of the Society for Political Methodology, Charlottesville, VA.

Ghanadan, Rebecca, and Jonathan G. Koomey. 2005. "Using Energy Scenarios to Explore Alternative Energy Pathways in California.” Energy Policy 33(9): 1117-1142.

Gilardi, Fabrizio. 2010. "Who Learns from What in Policy Diffusion Processes?" American Journal of Political Science 54(3): 650-666.

Golan, Guy. 2006. "Intermedia Agenda Setting and Global News Coverage: Assessing the Influence of the New York Times on Three Television Evening News Programs." Journalism Studies 7(2): 323-333.

Gomez-Rodriguez, Manuel, Jure Leskovec, and Andreas Krause. 2010. Inferring Networks of Diffusion and Influence. In The $16^{\text {th }}$ ACM SIGKDD Conference on Knowledge Discovery and Data Mining (KDD).

Graham, Erin R., Charles R. Shipan, and Craig Volden. 2013. "The Diffusion of Policy Diffusion Research in Political Science." British Journal of Political Science 43(3): 673-701.

Gray, Virginia. 1973. "Innovation in the States: A Diffusion Study." American Political Science Review 67(4): 1174-1185.

Grossback, Lawrence J., Sean Nicholson-Crotty, and David A. M. Peterson. 2004. "Ideology and Learning in Policy Diffusion.” American Politics Research 32(5): 521-545.

Hafner-Burton, Emilie M., Miles Kahler, and Alexander H. Montgomery. 2009. "Network Analysis for International Relations.” International Organization 63(3): 559-592.

Hero, Rodney E., and Caroline J. Tolbert. 1996. "A Racial/Ethnic Diversity Interpretation of Politics and Policy in the States of the U.S." American Journal of Political Science 40(3): 851871.

Hummon, Norman P. 2000. "Utility and Dynamic Social Networks.” Social Networks 22(3): 221249.

Karch, Andrew. 2007. Democratic Laboratories: Policy Diffusion Among the American States. Ann Arbor, MI: University of Michigan Press.

Karch, Andrew, Sean C. Nicholson-Crotty, Neal D. Woods, and Ann O’M. Bowman. 2013. "Policy Diffusion and the Pro-Innovation Bias." Presented at the Annual State Politics and Policy Conference, Iowa City, IA.

King, James D. 2000. "Changes in Professionalism in U.S. State Legislatures." Legislative Studies Quarterly 25(2): 327-343.

Kingdon, John W. 1973. Congressmen's Voting Decisions. New York: Harper \& Row.

Kirke, Deirdre M. 2004. "Chain Reactions in Adolescents? Cigarette, Alcohol and Drug Use: Similarity Through Peer Influence or the Patterning of Ties in Peer Networks?" Social Networks 26(1): 3-28.

Klarner, Carl. 2003. "The Measurement of the Partisan Balance of State Government." State Politics \& Policy Quarterly 3(3): 309-319.

Krackardt, David. 1987. "QAP Partialling as a Test of Spuriousness.” Social Networks 9(2): 171186. 
Lazer, David, and Allan Friedman. 2007. "The Network Structure of Exploration and Exploitation." Administrative Science Quarterly 52(4): 667-694.

Mason, Winter, and Duncan J. Watts. 2012. "Collaborative Learning in Networks." Proceedings of the National Academy of Sciences 109(3): 764-769.

Matthews, Donald R., and James A. Stimson. 1975. Yeas and Nays: Normal Decision-Making in the U.S. House of Representatives. New York: Wiley.

May, Peter J. 1992. "Policy Learning and Failure." Journal of Public Policy 12(4): 331-354.

Mintrom, Michael, and Sandra Vergari. 1998. "Policy Networks and Innovation Diffusion: The Case of State Education Reforms." Journal of Politics 60(1): 126-148.

Mooney, Christopher Z. 2001. "Modeling Regional Effects on State Policy Diffusion.” Political Research Quarterly 54(1): 103-124.

Neuman, W. Russell, Lauren Guggenheim, S. Mo Jang, and Soo Young Bae. 2014. "The Dynamics of Public Attention: Agenda-Setting Theory Meets Big Data.” Journal of Communication 64(2): 193-214.

Nicholson-Crotty, Sean. 2009. "The Politics of Diffusion: Public Policy in the American States." Journal of Politics 71(1): 192-205.

Nussbaum, Alex. 2007. "Scientists: State Must Act on Warming Now." The Washington Post. February 21.

Pacheco, Julianna. 2012. "The Social Contagion Model: Exploring The Role of Public Opinion on the Diffusion of Anti-Smoking Legislation across the American States." Journal of Politics 74(1): 187-202.

Rice, Ronald E., August E. Grant, Joseph Schmitz, and Jack Torobin. 1990. "Individual and Network Influences on the Adoption and Perceived Outcomes of Electronic Messaging." Social Networks 12(1): 27-55.

Ringe, Nils, Jennifer Nicoll Victor, and Justin H. Gross. 2013. "Keeping Your Friends Close and Your Enemies Closer? Information Networks in Legislative Politics." British Journal of Political Science 43(3): 601-628.

Shipan, Charles R., and Craig Volden. 2006. "Bottom-Up Federalism: The Diffusion of Antismoking Policies from U.S. Cities to States." American Journal of Political Science 50(4): 825-843.

Shipan, Charles R., and Craig Volden. 2012. "Policy Diffusion: Seven Lessons for Scholars and Practitioners." Public Administration Review 72(6): 788-796.

Simon, Herbert Alexander. 1976. Administrative Behavior: A Study of Decision-Making Processes in Administrative Organization. New York: Free Press.

Tam Cho, Wendy K., and James H. Fowler. 2010. "Legislative Success in a Small World: Social Network Analysis and the Dynamics of Congressional Legislation." Journal of Politics 72(1): 124-135.

Tan, Yue, and David H. Weaver. 2009. "Local Media, Public Opinion, and State Legislative Policies: Agenda Setting at the State Level.” The International Journal of Press/Politics 14(4): 454476.

Volden, Craig. 2006. "States as Policy Laboratories: Emulating Success in the Children's Health Insurance Program." American Journal of Political Science 50(2): 294-312.

Volden, Craig, Michael M. Ting, and Daniel P. Carpenter. 2008. "A Formal Model of Learning and Policy Diffusion." American Political Science Review 102(3): 319-332. 
Wagner, John. 2007. "Bills to Cut Pollution, Aid Bay, are Signed into Law." The Washington Post. April 25.

Walker, Jack L. 1969. "The Diffusion of Innovations Among the American States." American Political Science Review 63(3): 880-899. 
Figure 1: Pre-WV Adoption Times, 1975-2009

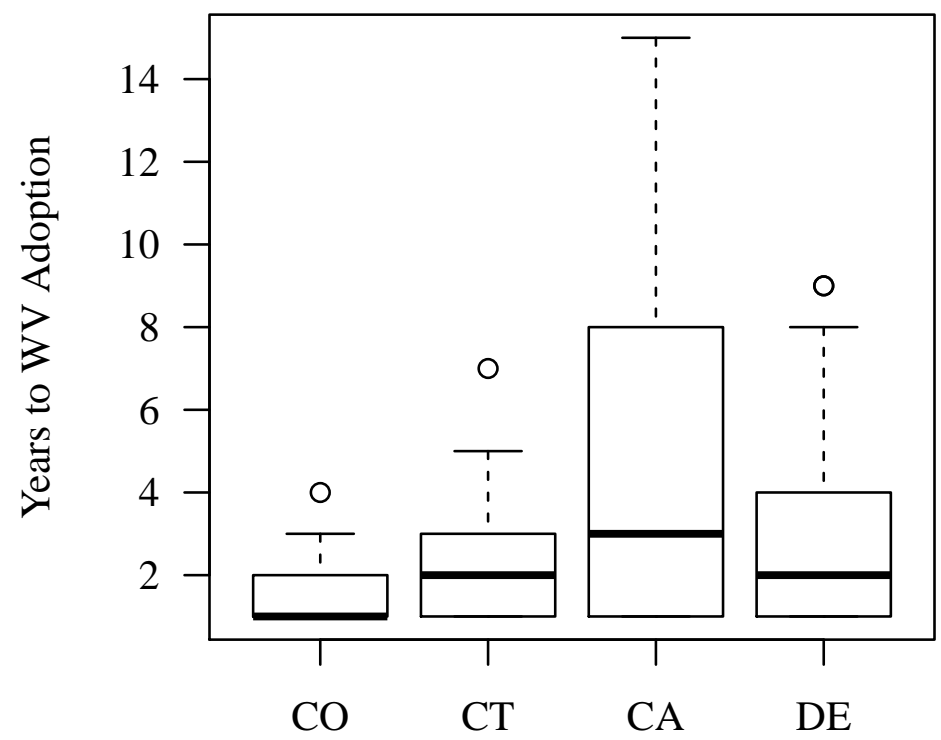

Note: Each box plot gives the distribution of time lags (in years) between the adoptions of the state listed on the $x$-axis and WV's adoptions for all policies that the state adopted prior to WV. 
Figure 2: Comparison of Diffusion Relations with Geographic Contiguity

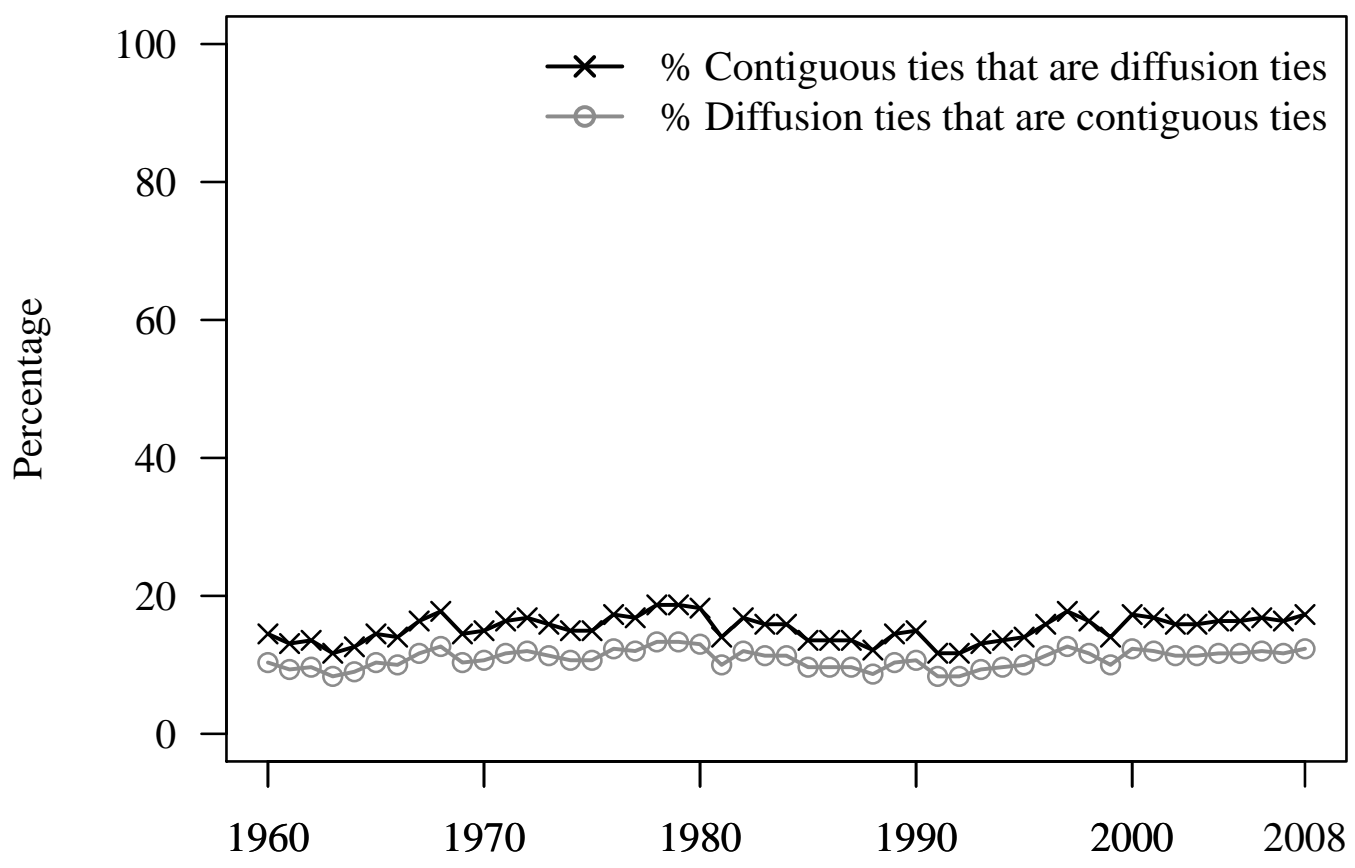

Note: The graph presents the percentage of contiguity relations between states that are identified as diffusion ties and the percentage of inferred diffusion ties that are between contiguous states. 
Figure 3: Association Between Inferred Diffusion Ties and Media Reports of Emulation

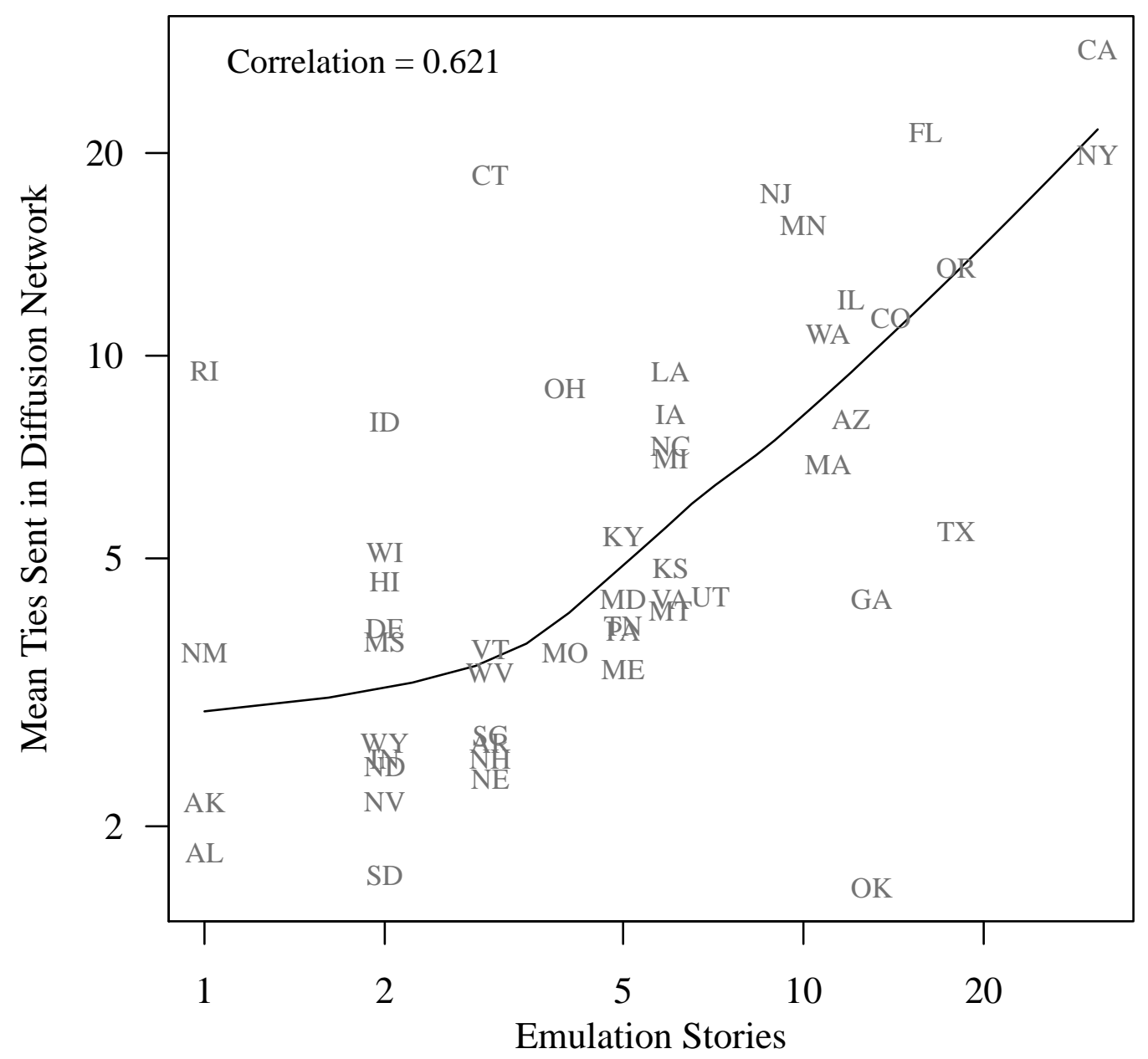

Note: Both axes are on the natural log scale. Because New York and California are large positive outliers on the linear scale, the correlation is computed on the natural $\log$ scale. The correlation on the linear scale is 0.72 . The line depicts a loess regression fit. 
Figure 4: Estimated Substantive Effects of Absolute Difference Variables
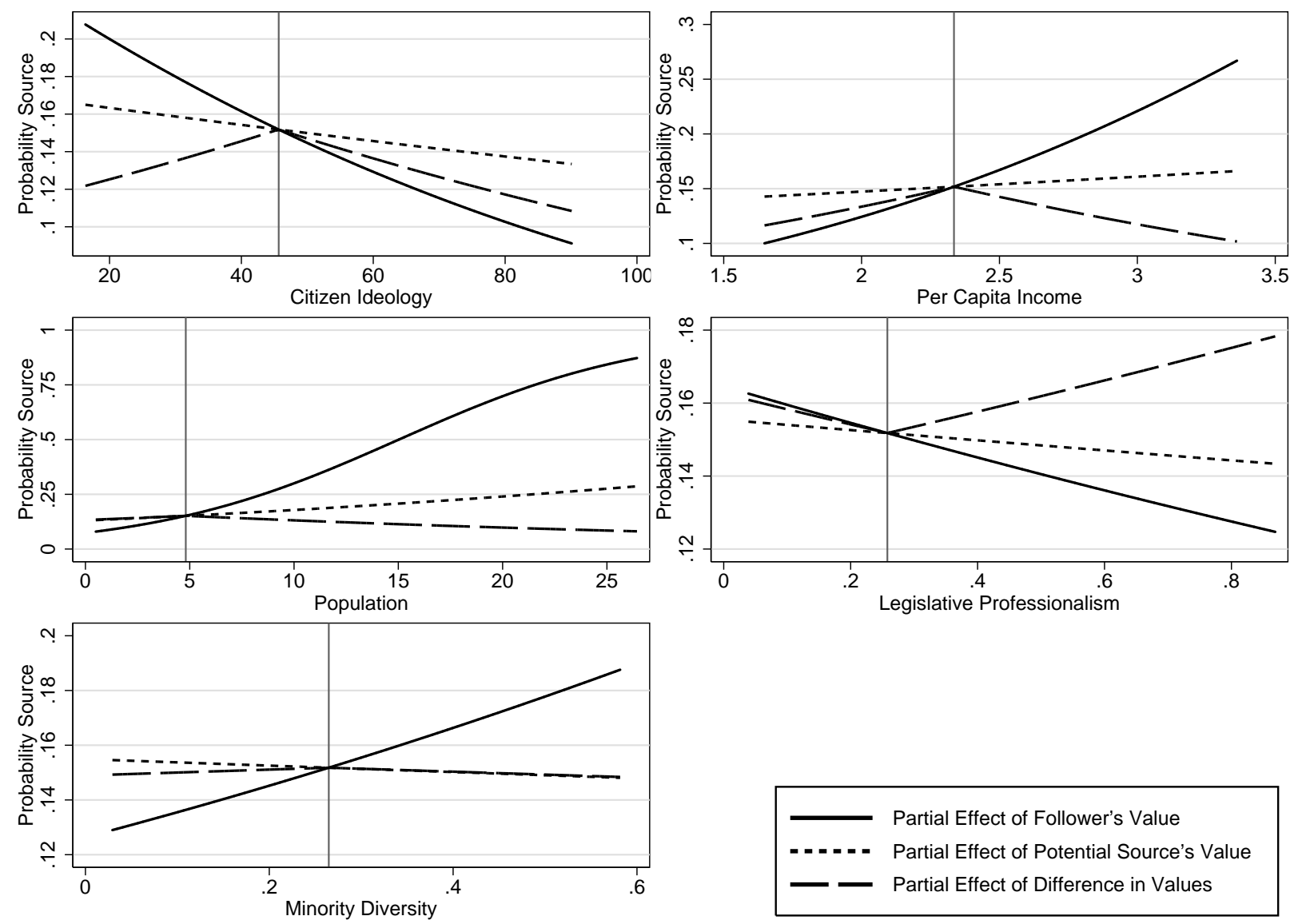

Partial Effect of Follower's Value

-. - . - . Partial Effect of Potential Source's Value

— Partial Effect of Difference in Values

Note: The graphs present the effects of each variable on the probability scale using Model 2's estimates. All other variables are set to their mean (continuous variables) or mode (binary variables) in 1985 and the random effects are set to zero. 
Figure 5: Estimated Substantive Effects of Selected Variables
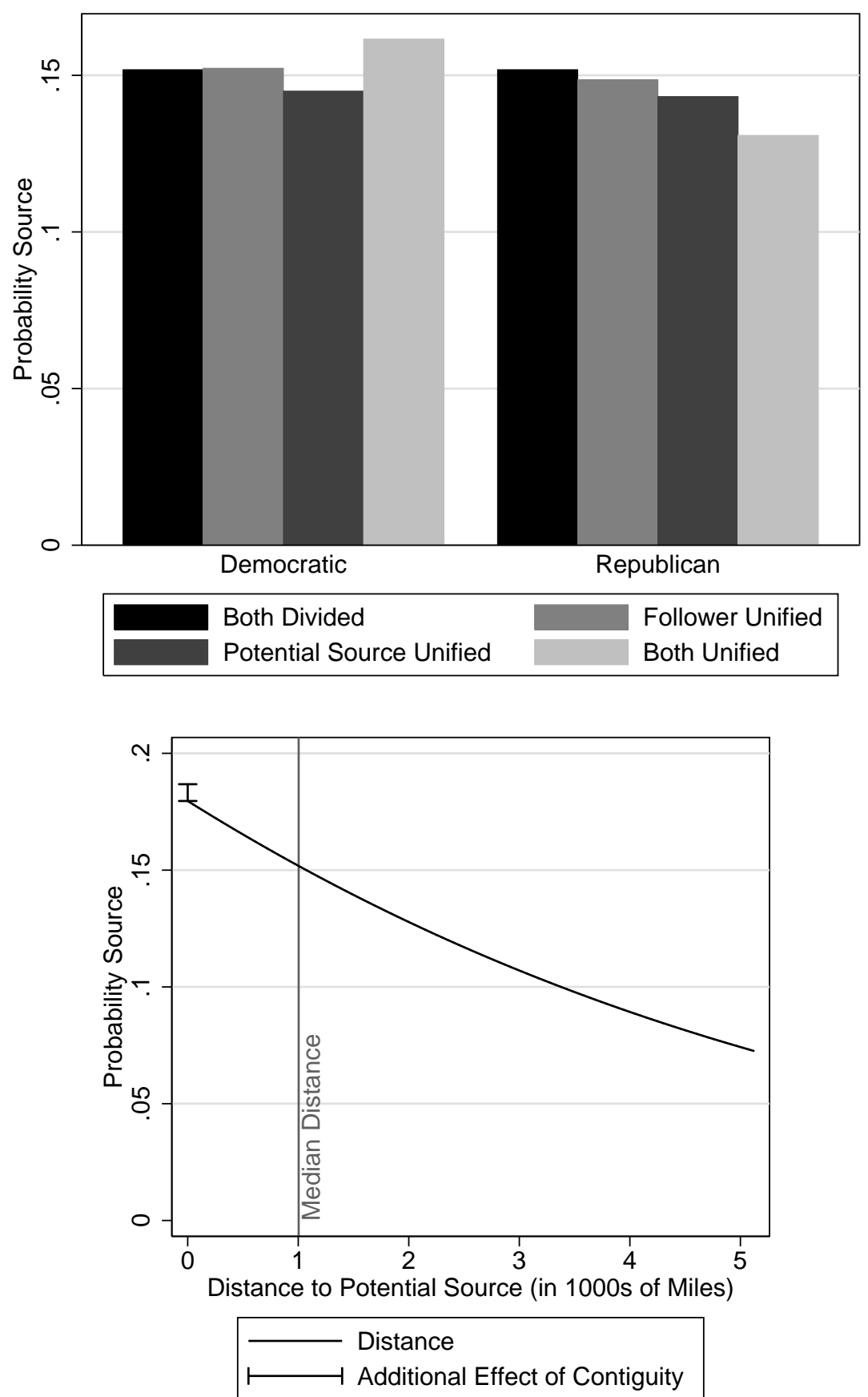

Note: The graphs present the effects of each variable on the probability scale using Model 2's estimates. All other variables are set to their mean (continuous variables) or mode (binary variables) in 1985 and the random effects are set to zero. 
Table 1: Top 15 States Based on the Total Number of Diffusion Ties Sent to Other States within Five-Year Periods

\begin{tabular}{rllllllllll}
\hline Rank & $60-64$ & $65-69$ & $70-74$ & $75-79$ & $80-84$ & $85-89$ & $90-94$ & $95-99$ & $00-04$ & $05-09$ \\
\hline 1 & NY & NY & NY & NY & NY & FL & FL & CA & CA & CA \\
2 & KY & KY & FL & FL & FL & NY & NY & CT & CT & CT \\
3 & CA & SC & CO & NJ & NJ & CA & CA & NJ & FL & NJ \\
4 & MN & AL & RI & MN & MN & MN & CT & FL & WA & FL \\
5 & AL & CO & CT & OR & RI & OR & OR & NY & NJ & WA \\
6 & SC & NM & MN & IL & OR & NJ & MN & MN & IL & IL \\
7 & RI & MN & MI & CO & CO & RI & NJ & OR & MN & MN \\
8 & MI & OH & NJ & AK & CA & CT & CO & WA & AZ & AZ \\
9 & VT & NJ & NE & NH & AK & AK & OH & LA & IA & LA \\
10 & NJ & WA & PA & RI & IL & IL & RI & CO & NC & IA \\
11 & IL & MI & LA & AR & LA & CO & IL & IA & OR & OH \\
12 & WA & RI & AL & CT & MI & ID & AK & AZ & CO & NC \\
13 & MD & MD & OR & MI & CT & MI & LA & NC & HI & CO \\
14 & OH & PA & MD & DE & ID & OH & MI & OH & LA & WI \\
15 & MS & VT & AR & MS & PA & KS & ID & ID & OH & UT \\
\hline
\end{tabular}


Table 2: Top Innovators from the Inferred Diffusion Network

\begin{tabular}{rrrrr}
\hline & FL & NY & CA & First Adopter \\
\hline FL & - & 7 & 5 & 13 \\
NY & 7 & - & 3 & 18 \\
CA & 6 & 14 & - & 24 \\
\hline
\end{tabular}

Note: The entry in row $i$, column $j$ of the state $\times$ state elements of this table gives the number of policies for which state $i$ was the first adopter and state $j$ never adopted. The last column gives the total number of policies for which state $i$ was the first adopter. 
Table 3: Multilevel Logit Models of State Policy Diffusion Ties

\begin{tabular}{|c|c|c|c|c|}
\hline & Coef. & S.E. & Coef. & S.E. \\
\hline \multicolumn{5}{|l|}{ Follower State Characteristics: } \\
\hline Citizen Ideology & & & $-0.013^{*}$ & $(0.002)$ \\
\hline Legislative Professionalism & & & -0.373 & $(0.240)$ \\
\hline Minority Diversity & & & $0.804^{+}$ & $(0.236)$ \\
\hline Per Capita Income & & & $0.692^{+}$ & $(0.094)$ \\
\hline Population & & & $0.168^{*}$ & $(0.011)$ \\
\hline Unified Democratic Government & & & 0.004 & $(0.034)$ \\
\hline Unified Republican Government & & & -0.025 & $(0.041)$ \\
\hline \multicolumn{5}{|l|}{ Potential Source Characteristics: } \\
\hline Citizen Ideology & & & $-0.003^{*}$ & $(0.001)$ \\
\hline Legislative Professionalism & & & -0.110 & $(0.216)$ \\
\hline Minority Diversity & & & -0.091 & $(0.182)$ \\
\hline Per Capita Income & & & 0.104 & $(0.074)$ \\
\hline Population & & & $0.037^{*}$ & $(0.008)$ \\
\hline Unified Democratic Government & & & -0.054 & $(0.034)$ \\
\hline Unified Republican Government & & & -0.068 & $(0.039)$ \\
\hline \multicolumn{5}{|l|}{ Relative Follower/Source Characteristics: } \\
\hline Contiguous & $0.152^{*}$ & $(0.039)$ & 0.048 & $(0.040)$ \\
\hline Distance & $-0.234^{*}$ & $(0.019)$ & $-0.201^{*}$ & $(0.020)$ \\
\hline Citizen Ideology (Absolute Difference) & & & $-0.009^{*}$ & $(0.001)$ \\
\hline Legislative Professionalism (Absolute Difference) & & & $0.315^{+}$ & $(0.139)$ \\
\hline Minority Diversity (Absolute Difference) & & & -0.084 & $(0.107)$ \\
\hline Per Capita Income (Absolute Difference) & & & $-0.445^{*}$ & $(0.048)$ \\
\hline Population (Absolute Difference) & & & $-0.033^{*}$ & $(0.004)$ \\
\hline Unified Democratic (Product) & & & $0.124^{+}$ & $(0.046)$ \\
\hline Unified Republican (Product) & & & -0.080 & $(0.082)$ \\
\hline Constant & $-1.922^{*}$ & $(0.137)$ & $-2.481^{+}$ & $(0.230)$ \\
\hline$\sigma_{u_{1}}($ Follower Random Effect) & 0.799 & & 0.826 & \\
\hline$\sigma_{u_{2}}($ Potential Source Random Effect) & 0.204 & & 0.214 & \\
\hline $\mathrm{N}$ & 122,5 & & 94,08 & \\
\hline \multicolumn{5}{|c|}{$\begin{array}{l}\text { Note: Observations are dyadic. The dependent variable indicates whether potential source state is a source for a } \\
\text { follower state in a given year. We use the network with } 300 \text { edges over } 35 \text { years of policy adoptions. Multilevel } \\
\text { logit coefficients are reported with standard errors in parentheses. }{ }^{+} \text {indicates statistical significance at the } 0.05 \\
\text { level (two-tailed) according to just the parametric } p \text {-values from the multilevel logit. }{ }^{*} \text { indicates statistical signif- } \\
\text { icance at the } 0.05 \text { level according to the QAP } p \text {-values and the parametric } p \text {-values. QAP } p \text {-values derived from } \\
500 \text { network permutations. }\end{array}$} \\
\hline
\end{tabular}




\title{
Online Appendix for: Persistent Policy Pathways: Inferring Diffusion Networks in the American States
}

\author{
Bruce A. Desmarais* $\quad$ Jeffrey J. Harden ${ }^{\dagger} \quad$ Frederick J. Boehmke
}

November 2, 2014

Forthcoming, American Political Science Review

\section{Latent Network Inference}

The derivation of the Net Inf algorithm begins with the definition of a probabilistic model describing how attributes would cascade through a diffusion network. To clarify application to state policy diffusion, we refer to the units and attributes in the model as states and policies, respectively. Denote a single policy cascade — the years in which states adopted a given policy—as $c$. The model is derived in three steps. First, we construct the probability that state $u$ spreads a policy to state $v: P_{c}(u, v)$. Second, given these dyadic spread probabilities, we build the probability that a policy spreads through the states in a given tree pattern $P(c \mid T)$, where $T$ specifies which states influence which other states. Third, we define $P(c \mid G)$, which is the probability of cascade $c$ given the diffusion network (i.e., graph) connecting the states $G$. With these three quantities defined, we can define a proper likelihood of the policy cascades given a proposed diffusion network by evaluating the probability of each cascade on that diffusion network.

The Net Inf algorithm assumes that diffusion occurs in continuous time and that diffusion

*Assistant Professor, Department of Political Science, University of Massachusetts-Amherst, 420 Thompson Hall, 200 Hicks Way, Amherst, MA 01003, desmarais@ polsci.umass.edu.

${ }^{\dagger}$ Assistant Professor, Department of Political Science, University of Colorado Boulder, 136 Ketchum, UCB 333 , Boulder, CO 80309, jeffrey.harden@ colorado.edu.

†Professor, Department of Political Science, and Director of the Social Science Program in the Public Policy Center, University of Iowa, 341 Schaeffer Hall, Iowa City, IA 52242, frederick-boehmke@uiowa.edu. 
time has an exponential distribution. If state $u$ adopts a policy at time $t_{u}$ and state $v$ adopts a policy at time $t_{v}\left(t_{v} \geq t_{u}\right)$ and $u$ spreads the policy to $v$, then the probability of the diffusion time $\left(t_{v}-t_{u}\right)$ is given by

$$
P_{c}(u, v)=\lambda \exp \left(\frac{-\left(t_{v}-t_{u}\right)}{\lambda}\right)
$$

where $\lambda$ is the rate parameter of the exponential distribution. Given this, the probability of observing a cascade that propagates in a given pattern over the states, represented by the tree $T$ that encodes $(i, j)$ pairs listing which states were influenced by which other states, is

$$
P(c \mid T)=\prod_{(i, j) \in T} P_{c}(i, j)
$$

The diffusion network $G$ places a constraint on the possible tree structures $T$ along which the policy can spread. That is, a policy cannot spread from $i$ to $j$ if there is not a diffusion pathway from $i$ to $j$ in $G$. Thus, to build the probability of a cascade $c$ given the diffusion network $G$, we average the probability of the cascade $c$ over all possible tree structures in $G$, denoted $\mathscr{T}(G)$.

$$
P(c \mid G)=\frac{1}{|\mathscr{T}(G)|} \sum_{T \in \mathscr{T}(G)} P(c \mid T)
$$

where $|\mathscr{T}(G)|$ is the number of tree structures that can be constructed from $G$. Given a set of policy cascades $(C)$, the likelihood of the cascade data given a proposed diffusion network $G$ is:

$$
P(C \mid G)=\prod_{c \in C} P(c \mid G)
$$

\section{Inferring the Network}

With the probabilistic model of diffusion along a diffusion network defined, the task of inferring a diffusion network is to find a network structure $G$ under which we would have been highly likely to observe the set of policy cascades $C$. Ideally, we would identify the network structure that maximized the likelihood of observing $C$. Likelihood maximization in this case, however, turns out 
to be a computationally intractable task. Among the 50 states, there are $2 \times 2^{1225}$ possible network structures. Moreover, Gomez-Rodriguez, Leskovec, and Krause (2010) show that every network structure would need to be evaluated to assure that the optimal network had been identified.

As a more computationally tractable alternative, Gomez-Rodriguez, Leskovec, and Krause (2010) derive an approach to approximation of the optimal $G$. They also demonstrate analytically and through simulations that this method is capable of inferring a very-close-to-optimal network structure inference within feasible compute times. Their departures from exhaustive optimization are two. First, instead of computing the likelihood of a cascade given a network structure by enumerating all possible propagation trees represented by that network structure, they simply focus on the most likely propagation tree for each cascade within a given network structure-a shortcut which they refer to as lazy evaluation. Second, they adopt a greedy (i.e., local) optimization approach that iteratively adds diffusion ties to the network structure $G$ such that the $k^{\text {th }}$ diffusion tie added to the network improves the likelihood function more than any other tie that could be added to the network, given the $k-1$ ties already in the network.

\section{Network Inference: Empirical Conditions}

In this section we present ancillary information regarding the application of Net Inf to the state policy diffusion data. Specifically, we present the complete model fit results from our tuning exercise as well as descriptive data regarding the number of policies and adoption instances used to draw inferences in each year.

\section{Net Inf Parameter Tuning}

We set three parameters in the network inference procedure. First, we need to define the number of preceding years of adoptions (denoted $k$ ) that will be used to infer the network for time $t$. Second, we need to define the number of edges $(E)$ we want to infer in each time period. Third, we need to tune a rate parameter $\lambda$ of the exponential distribution used by Net In $f$ to calibrate how long it takes for policies to diffuse from one state to another. A policy can only diffuse from $i$ to $j$ if there is an edge from $i$ to $j$ in the inferred network. The exponential distribution gives the distribution 
of diffusion times between states, provided that there is an edge connecting them. Higher rates place a higher penalty on the addition of edges to the network along which it takes a long time for policies to diffuse. This prevents any given adoption by one state that happens to fall later in time than adoption by another state from contributing to the formation of a tie between the two states.

We take a data-driven approach to finding optimal values of these parameters. We use the conventional discrete-time event history modeling methodology to evaluate the performance of the network in predicting future adoptions measured at different parameterizations. For each unique combination of parameters $\{k, E, \lambda\}$, we fit a pooled (across all policies in the data) logistic discrete-time event history model predicting policy adoption. The model contains three classes of regressors. For state $s$ still in the data at time $t$ for policy $p$, the regressors are:

(1) States Adopting: The number of other states that have adopted by time $t-1$,

(2) Sources Adopting: In a network inferred on all adoptions between $t-k$ and $t-1$, the number of $s$ 's sources in the network that have adopted $p$.

(3) Policy Area: An indicator variable that models the unique rate of adoption for each policy.

In this design, all of the adoptions used to infer the network used to predict adoptions at time $t$ occurred prior to $t$. We use a simple grid search to find best-fitting values of $\{k, E, \lambda\}$. We search over $\lambda \in\{0.125,0.25,0.5,1\}$, which corresponds to mean diffusion times of $8,4,2$, and 1 years, respectively, $k \in\{5,10, \ldots, 50\}$, and $E \in\{100,200, \ldots, 1000\}$. We use the Bayesian Information Criterion (BIC) to evaluate the fit of each combination of parameters and search for the combination of parameters that best fits the data (i.e., results in the lowest BIC). Figure A.1 depicts the BIC values for all of the parameter combinations that we consider.

[Insert Figure A.1 here]

The network that results in the best predictive fit, across all values of $\lambda$ is one with 300 edges and defined over 35 years of policy adoptions. ${ }^{1}$ The fit is not particularly sensitive to the rate

\footnotetext{
${ }^{1}$ We also use a network based on 400 edges and 10-year periods for use in two applications to policy diffusion models (see below).
} 
parameter, but the network using a rate of 0.5 results in the best fit. This means that policies diffuse, on average, in two years. An average of approximately 1,900 adoption instances over an average of approximately 120 policies is used to infer the network for each year.

\section{Policies and Adoptions Used in Net Inf Over Time}

Figure A.2 gives the number of unique policies and the total number of adoption instances used to infer the diffusion network in each year. The network inferred toward the end of the time series is generally based on more data than the network earlier on in the series.

[Insert Figure A.2 here]

\section{Checking for Heterogeneity in Diffusion Classes}

As the heterogeneity in the results from models of policy diffusion in the state politics literature suggests, there is considerable variation in the processes that drive the diffusion of different policies. It is therefore important to check whether we are inappropriately pooling policies to infer a single diffusion network. Though we know that policies vary in terms of the patterns and predictors of diffusion, we must evaluate whether this variation is policy-specific and idiosyncratic with respect to the underlying diffusion network, or whether there are systematic and consistent cross-policy differences. In other words, we need to check whether there are different classes of policies in terms of the underlying diffusion network.

We use a probabilistic mixture modeling approach (Imai and Tingley 2012) to examine whether there are multiple classes of policies in terms of their effects on the inferred diffusion network. We iteratively remove each policy from the dataset and infer a new network with 300 edges that spans the entire time period in our data. For each policy, we have a network inferred without that policy included. If two (or more) policies affect the diffusion network in the same way, the inferred network should change in systematically similar ways when those two policies are removed from the dataset. Using a policies $\times$ potential edges $-187 \times 2,450$ - observation dataset, we fit a Bernoulli 
mixture model with the likelihood

$$
l(\mathbf{y}, \alpha, \pi)=\prod_{i=1}^{50} \prod_{j \neq i} \prod_{p=1}^{187} \sum_{a=1}^{k} \alpha_{a p} \pi_{i j a}^{y_{i j p}}\left(1-\pi_{i j a}\right)^{\left(1-y_{i j p}\right)}
$$

where $y_{i j p}$ is an indicator of whether there is a diffusion tie from $i$ to $j$ when policy $p$ is removed from the dataset, $k$ is the number of classes (i.e., mixture components) included in the model, $\alpha_{a p}$ is the probability that policy $p$ is a member of class $a$, and $\pi_{i j a}$ is the probability that there is an edge from $i$ to $j$ in networks inferred excluding policies in class $a$.

We estimate models with $k \in\{1,2, \ldots, 15\}$. The R package flexmix (Leisch 2004) is used to fit the models. Estimation also requires an initial assignment of the component membership probability for each policy. We use k-means clustering to identify initial cluster memberships, then assign the component membership cluster probability for each policy according to $\alpha_{a p}^{0}=$ $\frac{\lambda^{\mathbf{1}\left(c_{p}=a\right)}}{\sum_{i=1}^{k} \lambda^{\mathbf{1}\left(c_{p}=i\right)}}$, where $c_{p}$ is the initial cluster assignment of policy $p$ and $\lambda$ is a weight that controls the entropy in the initial component assignment probabilities, with higher values of $\lambda$ corresponding to lower entropy. We evaluate models with 10 values of $\lambda$, varied equally between 1 and 5 . The model fit results of the mixture modeling are presented in Figure A.3. Following Fraley and Raftery (1998), we evaluate the fit of each model using the BIC.

\section{[Insert Figure A.3 here]}

Across all values of $\lambda$, the best fitting model is clearly the one with only one component. This indicates that, insofar as removing individual policies changes the results of the network inference, the network is changed in ways that are idiosyncratic with respect to the other policies. In other words, policies do not appear to affect the network in patterns that can be efficiently grouped into a discrete number of classes, aside from the overall patterns that cut across all policies. These results support our use of a single diffusion network to model the diffusion patterns across all of the policies in our dataset. 


\section{Adjusting for Total State Coverage in the LexisNexis Analysis}

In Table A.1, we present ordinary least squares regression results in which we regress the number of emulation stories identified in LexisNexis on the mean number of diffusion ties sent in the diffusion networks and the total number of search hits of a state's name in LexisNexis Academic. This analysis adjusts for the influence of overall state coverage on the number of reported diffusion ties.

[Insert Table A.1 here]

Table A.2 reports the news outlets in which we identify emulation stories from the LexisNexis database.

[Insert Table A.2 here]

\section{Applying the Inferred Network to Models of Policy Diffusion}

Here we present our replications of the five policy diffusion EHA models. Recall from the main text that we replicated four policy-specific models: lotteries (Berry and Berry 1990), Indian gaming (Boehmke 2005), capital punishment (Boehmke 2005), and restaurant smoking bans (Shipan and Volden 2006). ${ }^{2}$ We also replicated Boehmke and Skinner's (2012) "pooled event history analysis" (PEHA) model fit to data on 151 different policies diffusing over the period 1960-1999 (see also Boehmke 2009). This approach stacks the data from different policies and estimates a unified model with a common set of independent variables (including state, year, and policy fixed effects). Pooling the data does result in fewer independent variables than for any single policy, but it provides insight into what factors affect diffusion most broadly across the issue spectrum of American politics. We show below that information from our inferred diffusion network is one of those factors.

\footnotetext{
${ }^{2}$ Specifically, we replicate the following models: Berry and Berry (1990, 409), Table 1, model 1; Boehmke (2005, 85 and 89), Tables 4.2 and 4.4; Shipan and Volden (2006, 839), Table 3, model 9.
} 


\section{Model Details}

We focus on these five models for several reasons. First, the four policy-specific models represent a wide variety of policies, and the pooled model represents an even wider range. Thus, we examine whether the diffusion network has a broad or narrow impact on adoption. Second, the original studies presenting the policy-specific models are well-known in the policy diffusion literature, having each garnered at least 60 citations according to Google Scholar. ${ }^{3}$ Finally, the models all use similar EHA empirical specifications, enhancing comparability. The dependent variable in each is coded " 1 " if a state adopted the policy in a given year and " 0 " otherwise, with states that have already adopted dropping out of the data beginning in the year after adoption. ${ }^{4}$

The theories underlying our replication models each have their own unique characteristics. To conserve space, we refer readers to the original studies for detailed discussions of each. We focus here on comparing the effect of the diffusion network on adoption to that of a factor that consistently appears in these models: geographic contiguity. Nearly all studies of policy diffusion include in their models either the number of or percentage of neighboring states that have previously adopted the policy. The expectation for this variable is that, due to economic competition and/or policy learning, as more neighbors adopt, the probability of a state adopting increases (see, for example, Berry and Berry 1990, 403-404; Boehmke 2005, chapter 4; Shipan and Volden 2006, 828).

It is unlikely that states can only compete with and learn from states with whom they share a border. Indeed, Berry and Berry (1990) point out that there are many plausible means of stateto-state influence, including shared borders, a shared region, or even shared culture. They further suggest that it would be useful to have a measure of which states a state tends to "follow" in policy adoption. With information on "predesignated leader states" in regions, the authors "would hypothesize that a state's probability of adopting a lottery increases after one or more states with a

\footnotetext{
${ }^{3}$ In fact, Berry and Berry (1990) is included on the "high impact" list of most influential articles appearing in the American Political Science Review (Sigelman 2006).

${ }^{4}$ The Berry and Berry (1990) and Boehmke (2005) models are estimated with probit and the Shipan and Volden (2006) and Boehmke and Skinner (2012) models are estimated with logistic regression.
} 
reputation as a leader within its region adopt it" (Berry and Berry 1990, 403). However, they also acknowledge that they have no means of measuring this concept because there are no "reliable data about which states are perceived... to be regional leaders in a policy area" (Berry and Berry 1990, 403).

\section{Including Network Information}

Our inferred policy diffusion network provides those data that previous scholars of policy diffusion have not had available. In fact, beyond simply measuring regional leaders, the network gives information on any state that tends to be a leader, or source, of policy innovation for another state. In our replications we incorporate information from the estimated diffusion network by creating a variable on the same scale as Neighbors Adopting: the number of a state's sources in a given year that previously adopted the policy. We use the inferred network to produce a list of states that influence the state in a specified time period immediately preceding a given year. ${ }^{5}$ This list represents all of that state's sources at that time. Next, to create the variable Sources Adopting we count the number of states from that list that have previously adopted the policy. We also computed this measure as a percentage, similar to studies that compute the percentage of Neighbors Adopting (e.g., Shipan and Volden 2006). We present both sets of results below (our substantive conclusions do not change).

After creating the Sources Adopting variable, we then add it to each of the five replication models. Recall that we avoid endogeneity problems because we only use adoptions that occurred before a given year to measure the network for that year. As such, the adoption of policy $j$ by state $i$ at time $t$ cannot inform the network used in the diffusion models to predict the adoption of policy $j$ by state $i$ at time $t$. The adoptions used in the network for time $t$ occur prior to $t .^{6}$

\footnotetext{
${ }^{5}$ As mentioned above, we constructed a version using 35-year periods and one with 10-year periods. Results between the two are generally very similar. For each model we used the version that produced the lowest AIC and BIC values (35-year version for the lotteries, capital punishment, and pooled models; 10-year version for the Indian gaming and smoking ban models).

${ }^{6}$ We include all policies in the construction of the network used to produce Sources Adopting, including the policy of interest in the EHA model. We also estimated the models after having removed the policy area of interest and found results that are virtually identical to what we present below.
} 


\section{Estimates and Model Fit}

We first examine the extent to which the inclusion of Sources Adopting-instead of or in addition to Neighbors Adopting —improves model fit. ${ }^{7}$ Table A.3 reports coefficient estimates and standard errors for the two variables as well as model fit statistics for three specifications: (1) the original model with Neighbors Adopting (plus the authors' other covariates), (2) a model with Sources Adopting substituted for Neighbors Adopting (plus the other covariates), and (3) a model with both Neighbors Adopting and Sources Adopting (plus the other covariates). In all cases the coefficients are positive (as expected), though statistical significance varies somewhat across specifications and replications. We assess the substantive impact of these effects in section .

\section{[Insert Table A.3 here]}

To compare model fit we compute AIC, BIC, and cross-validated percent correctly classified. We compute this last measure via leave-one-out cross-validation, which involves iteratively dropping one observation, estimating the model, computing an expected probability from that model for the left-out observation, then generating a predicted value of the dependent variable based on a single draw from the Bernoulli distribution with that expected probability. We then compute the percentage of the observations for which the prediction matches the actual dependent variable value. Thus, unlike information-based measures of fit such as AIC and BIC, this measure assesses each specification's capacity to make out-of-sample predictions. In Table A.3, the values in bold indicate the best-fitting model according to each statistic.

The AIC and BIC values support the inclusion of Sources Adopting in all but the restaurant smoking ban model, where the original model and the model with Sources Adopting produce AIC and BIC values within 2 units of each other, indicating equal fit. The cross-validated percent correctly classified measure also generally supports the inclusion of Sources Adopting. In four of the five replication models the percent correctly classified in one or both models with Sources Adopting increases from the original model with Neighbors Adopting (the restaurant smoking ban model is

\footnotetext{
${ }^{7}$ The question of whether Sources Adopting should replace or complement Neighbors Adopting is contextdependent. We focus on model fit here, but theoretical expectations should also be an important guide.
} 
again the lone exception). These improvements are somewhat small in magnitude—ranging from +1 to +3 percentage points across the different models. Nonetheless, they consistently point to the models that include Sources Adopting in the specification as the best fit.

Overall, Table A.3 provides good evidence that Sources Adopting can improve the fit of policy diffusion EHA models, either in place of or in addition to Neighbors Adopting. Importantly, across the five models, none of the fit statistics decisively selects the original model with Neighbors Adopting as the better fit. Given this evidence that Sources Adopting is a useful addition to diffusion models, our next step is to examine its substantive impact on policy adoption.

\section{Marginal Effects}

We examine the substantive implications of including Sources Adopting in Figure A.4 by graphing the average marginal effects of Neighbors Adopting (top row) and Sources Adopting (bottom row) in each model on the probability scale. ${ }^{8}$ All estimates are computed from the specifications that include either Neighbors Adopting or Sources Adopting. ${ }^{9}$

\section{[Insert Figure A.4 here]}

The first point to note from Figure A.4 is the effect of the count of Neighbors Adopting (lotteries, Indian gaming, capital punishment, and pooled model) and percentage of Neighbors Adopting (restaurant smoking bans) is positive. Consistent with the expectation that states react to economic competition and/or policy learning, more neighboring states with the policy corresponds with an increase in the probability of adoption. The magnitude and level of uncertainty varies somewhat across the models, but the effect is consistently in the positive direction.

Moving to the bottom row of Figure A.4, note that when substituted for Neighbors Adopting, the effect of Sources Adopting is also positive in all five models; as the number of sources adopting the policy increases, so too does probability of a state adopting the policy. From the minimum (0) to the maximum (lotteries: 7 , Indian gaming: 10, capital punishment: 10, restaurant smoking bans:

\footnotetext{
${ }^{8}$ We employ the "observed value" method of Hanmer and Kalkan (2013) in these computations. Rather than setting the other variables in the models to particular values (e.g., their means or modes), we allow them to vary naturally over the observed values for every case in the data, then compute the average expected probability for each observed value of Neighbors Adopting and Sources Adopting, respectively.

${ }^{9}$ Results with both included in the same model are substantively similar (see below).
} 
9, pooled model: 14) of Sources Adopting, the probability of adoption increases by the following percentage points, on average: 24 (lotteries), 24 (Indian gaming), 50 (capital punishment), 16 (restaurant smoking bans), and 11 (pooled model). As with the effect of Neighbors Adopting, the confidence intervals indicate varying degrees of uncertainty around these estimates. ${ }^{10}$ Nonetheless, these graphs show that Sources Adopting exerts a substantively significant, positive impact on the probability of adoption across many different policies.

Moreover, these positive effects remain even after controlling for Neighbors Adopting (see below). In short, these replication results show that information from our policy diffusion network can make a valuable contribution to diffusion studies. We show examples from four specific policy areas and a 151-policy pooled model in which states utilize a persistent set of diffusion sources to guide their policymaking decisions.

\section{Marginal Effects with Neighbors and Sources}

Figure A.5 presents the average marginal effects of Neighbors Adopting and Sources Adopting on the expected probability of adoption, controlling for the other (i.e., from the models in column 3 of Table A.3). Note that results are substantively similar to those in Figure A.4, which presents results from models with one variable or the other.

\section{[Insert Figure A.5 here]}

\section{Replication Results with Percentage of Sources Adopting}

Table A.4 presents the coefficient estimates and model fit statistics for the replication models using the percentage of sources (rather than number of sources) adopting the policy as the independent variable of interest. To maintain consistency we use the original authors' operationalization of the neighbors variable, which is a count in all but Shipan and Volden (2006). In an actual analysis we recommend that researchers use the same operationalization (count or percentage) for neighbors and sources.

Overall, these results are consistent with the results using the number of sources (see Table

\footnotetext{
${ }^{10}$ This is at least partially due to the fact that policy adoption models tend to have many independent variables (the median is 19 in the four policy-specific replications).
} 
A.3): including the source variable in the model produces a positive (and often statistically significant) coefficient estimate and improves model fit.

\section{[Insert Table A.4 here]}

We do not for advocate one measure over the other, but rather defer to individual researchers in making the choice based on theoretical and empirical considerations. The two approaches represent very different views on the diffusion process. The percentage measure specifies a diffusion process where the non-adopting neighbors (sources) have just as much influence as the adopting neighbors (sources) and the state ends up being pulled between the two. The count-based measure assumes that non-adopting neighbors (sources) do not influence a state's decision to adopt. If a researcher thought that states are only affected by their sources who adopt a particular policy, the count measure would likely make the most sense. In contrast, if states look to both their adopting and non-adopting sources, the percentage-based measure may be more appropriate.

\section{Fixed Effects Logit Results}

Table A.5 presents results using a source and follower fixed-effects logit model. Overall, results are consistent with those reported in the main text.

[Insert Table A.5 here] 


\section{References}

Berry, Frances Stokes, and William D. Berry. 1990. "State Lottery Adoptions as Policy Innovations: An Event History Analysis." American Political Science Review 84(2): 395-415.

Boehmke, Frederick J. 2005. The Indirect Effect of Direct Legislation: How Institutions Shape Interest Group Systems. Columbus, OH: The Ohio State University Press.

Boehmke, Frederick J. 2009. "Policy Emulation or Policy Convergence? Potential Ambiguities in the Dyadic Event History Approach to State Policy Emulation." Journal of Politics 71(3): 1125-1140.

Boehmke, Frederick J., and Paul Skinner. 2012. "The Determinants of State Policy Innovativeness." Presented at the Annual State Politics and Policy Conference, Houston, TX.

Fraley, Chris, and Adrian E. Raftery. 1998. "How Many Clusters? Which Clustering Method? Answers Via Model-Based Cluster Analysis.” The Computer Journal 41(8): 578-588.

Gomez-Rodriguez, Manuel, Jure Leskovec, and Andreas Krause. 2010. Inferring Networks of Diffusion and Influence. In The $16^{\text {th }}$ ACM SIGKDD Conference on Knowledge Discovery and Data Mining (KDD).

Hanmer, Michael J., and Kerem Ozan Kalkan. 2013. "Behind the Curve: Clarifying the Best Approach to Calculating Predicted Probabilities and Marginal Effects from Limited Dependent Variable Models." American Journal of Political Science 57(1): 263-277.

Imai, Kosuke, and Dustin Tingley. 2012. "A Statistical Method for Empirical Testing of Competing Theories." American Journal of Political Science 56(1): 218-236.

Leisch, Friedrich. 2004. "FlexMix: A General Framework for Finite Mixture Models and Latent Class Regression in R.” Journal of Statistical Software 11(10): 1-18.

Shipan, Charles R., and Craig Volden. 2006. "Bottom-Up Federalism: The Diffusion of Antismoking Policies from U.S. Cities to States." American Journal of Political Science 50(4): 825-843.

Sigelman, Lee. 2006. “Top Twenty Commentaries.” American Political Science Review 100(4): 667-687. 
Figure A.1: BIC of the Pooled Discrete Time Event History Models

(a) $\lambda=0.125$
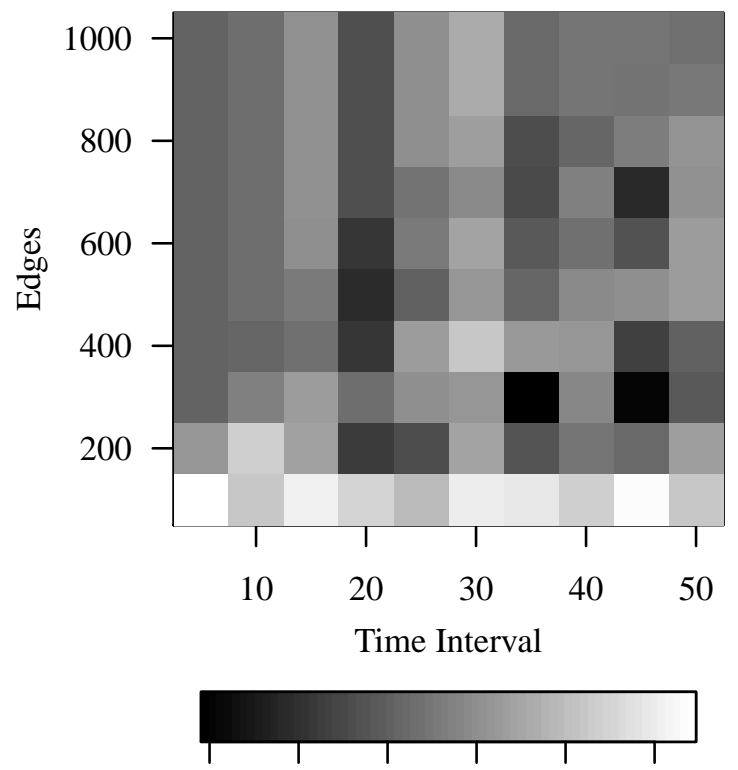

$20010 \quad 20030 \quad 20050$

(c) $\lambda=0.50$
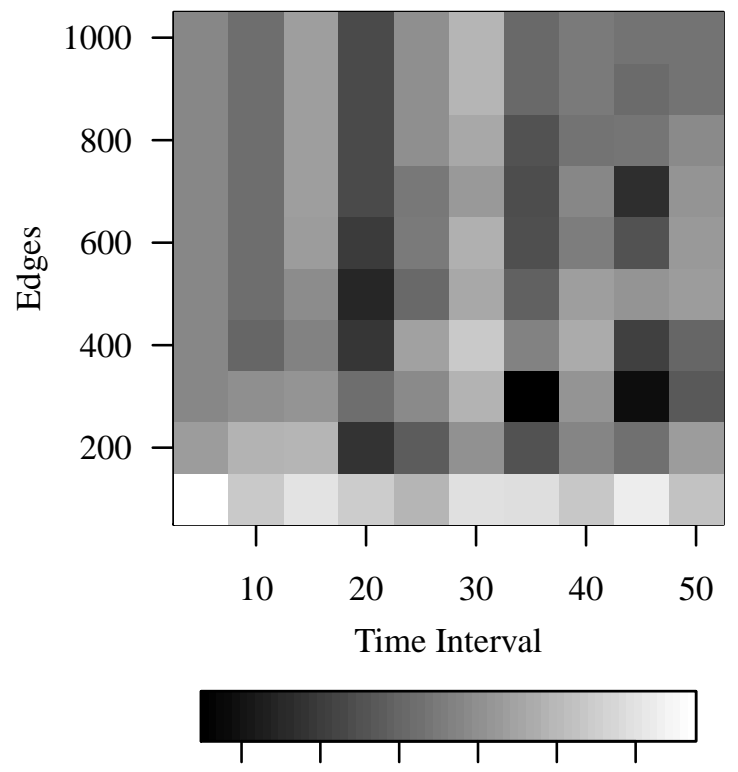

$20010 \quad 20030 \quad 20050$ (b) $\lambda=0.25$
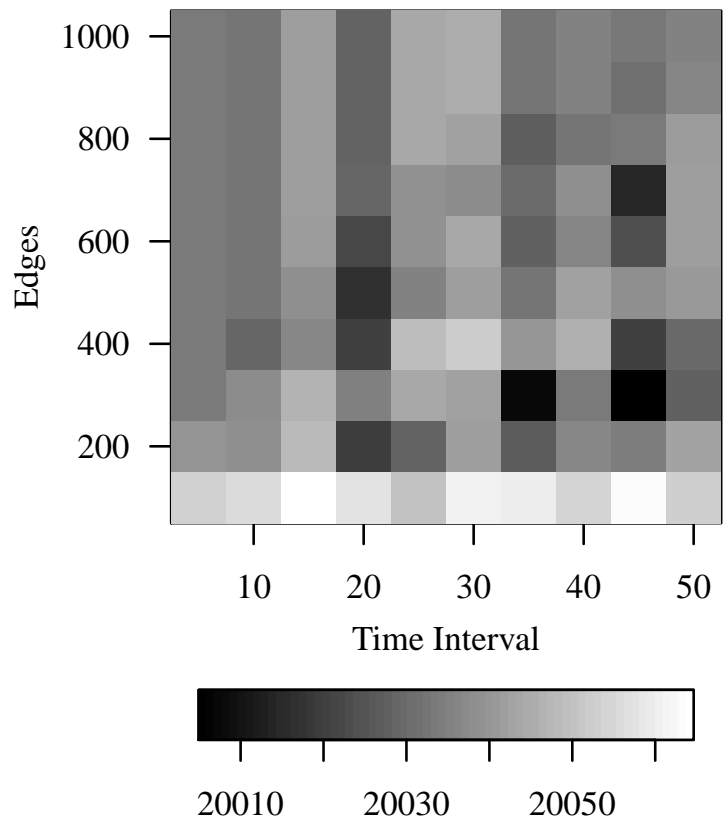

(d) $\lambda=1$
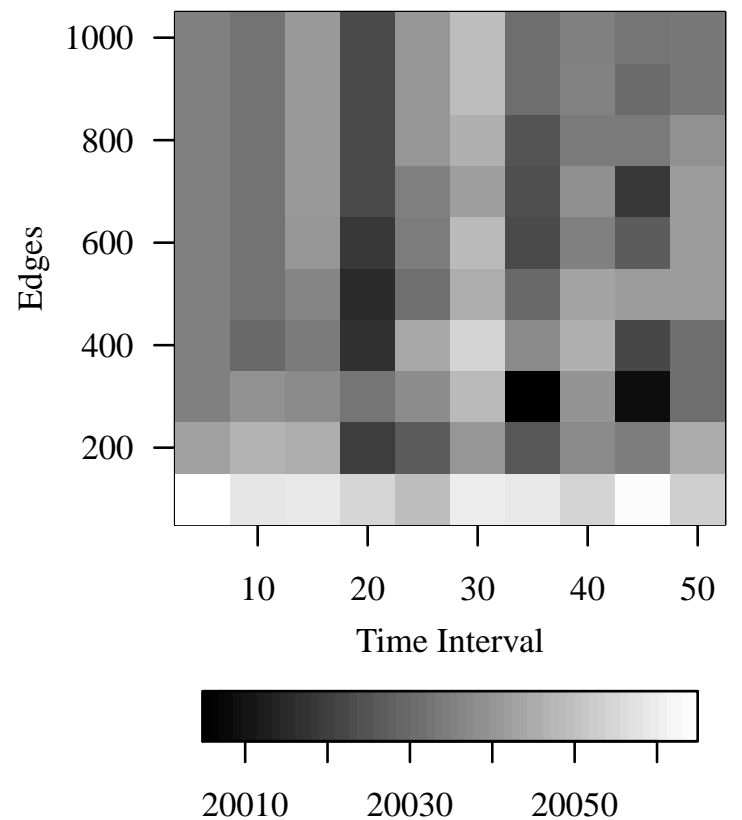

Note: There are 187 policies and 65,885 observations in each model. 


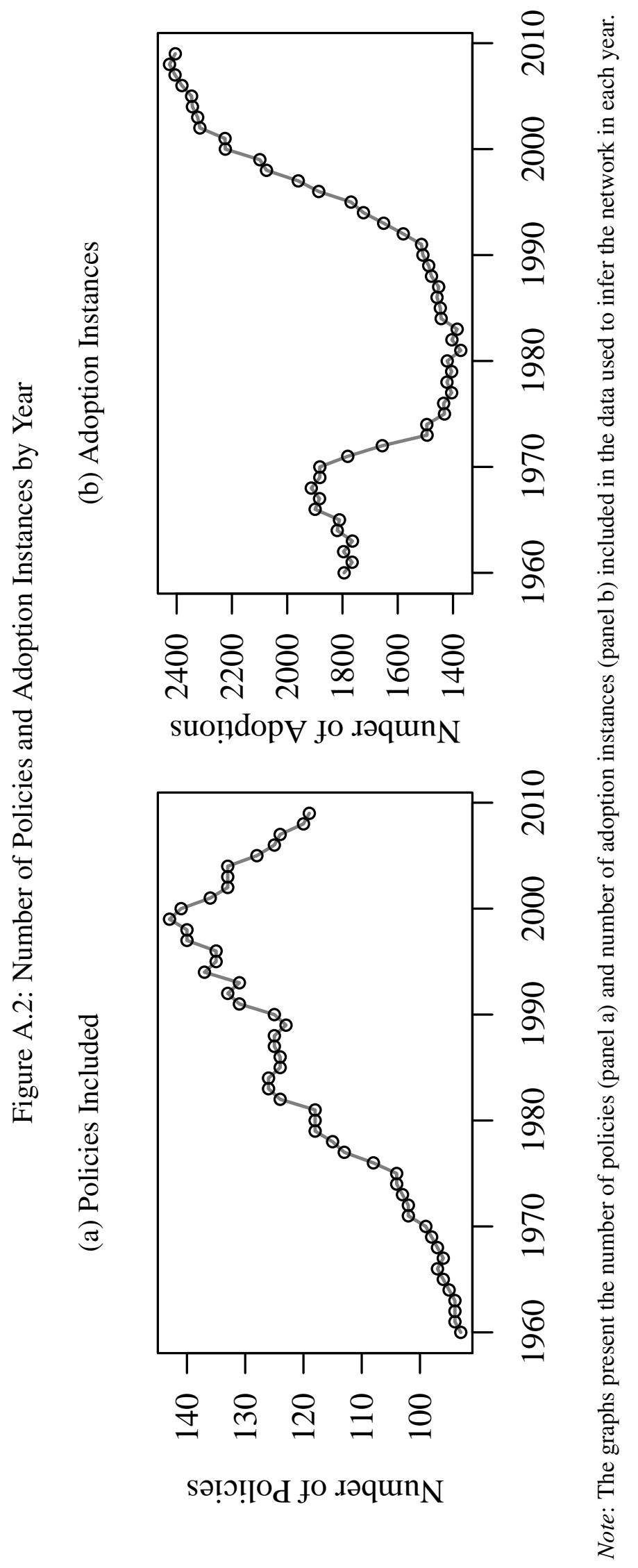


Figure A.3: Mixture Model Fit

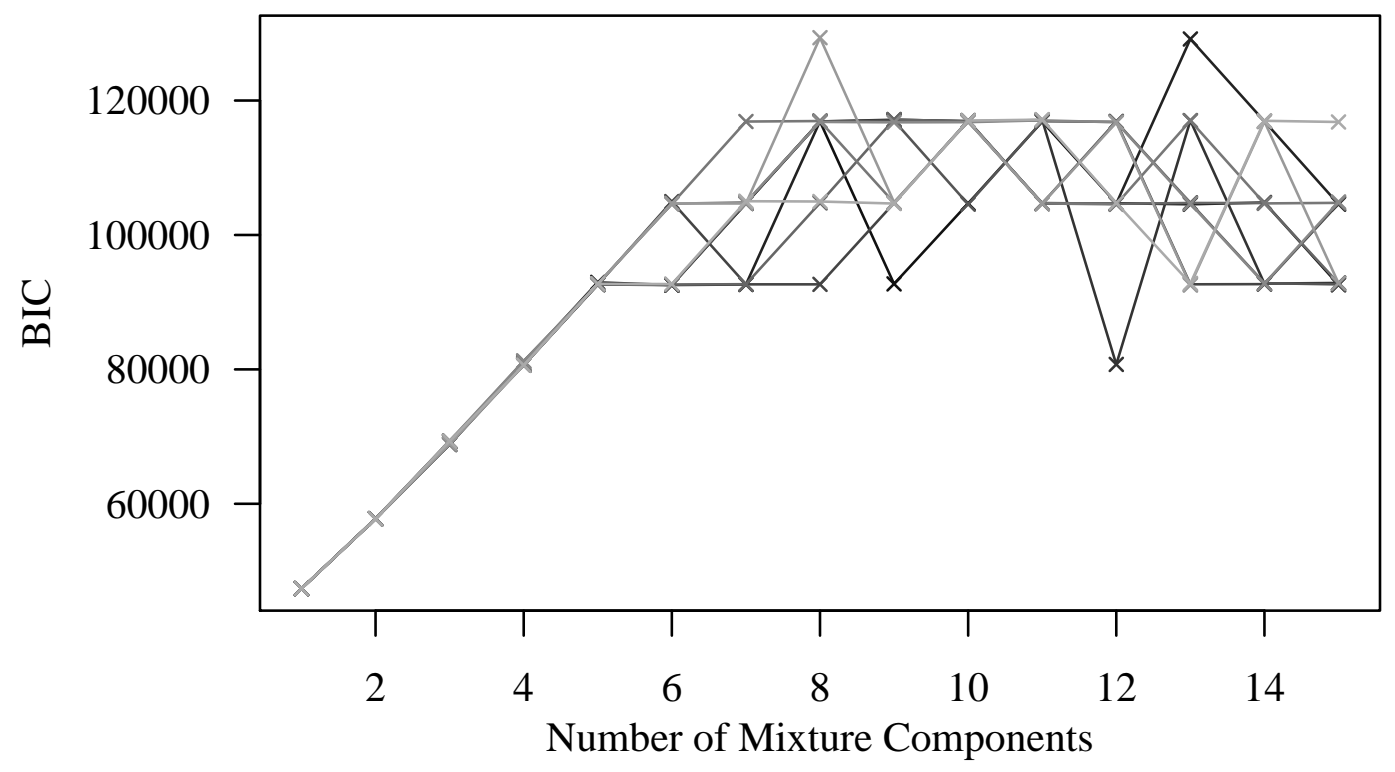

Note: Different line shades correspond to different values of $\lambda$, the parameter that controls the entropy in the initial cluster assignment probabilities. 


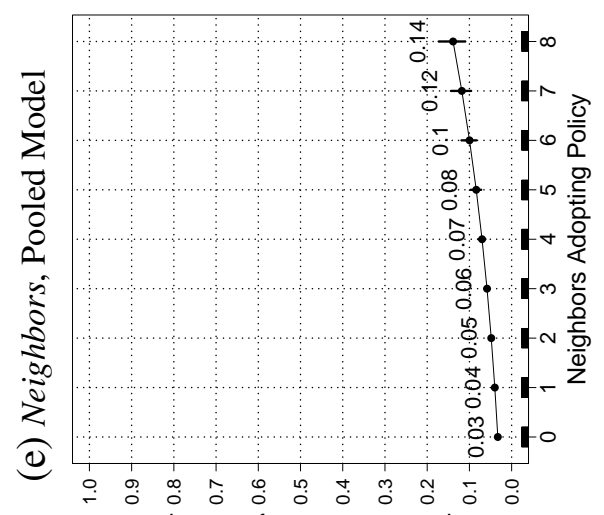

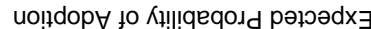

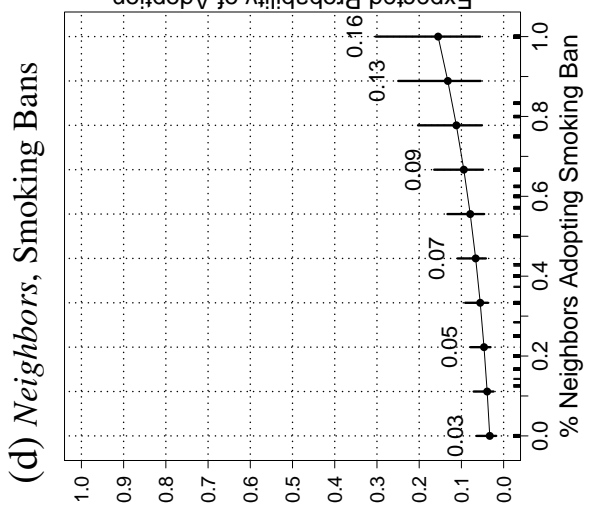

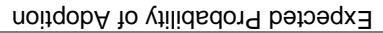

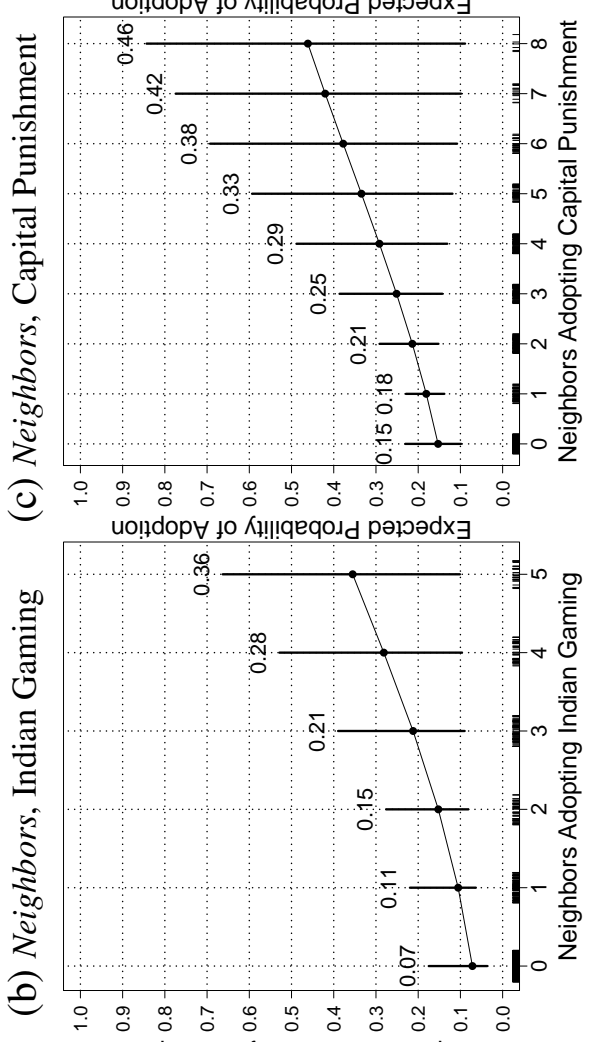

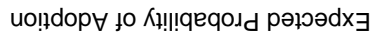

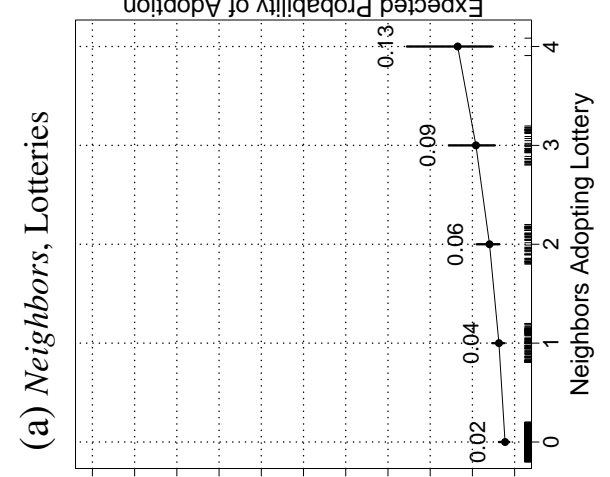

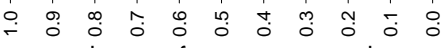

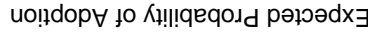

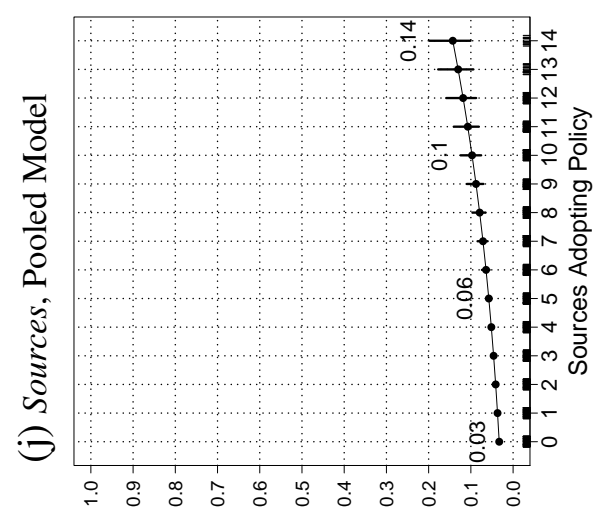

官.

2

ไิ่

m

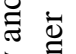

空寻

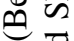

品

氖

uolldopy fo

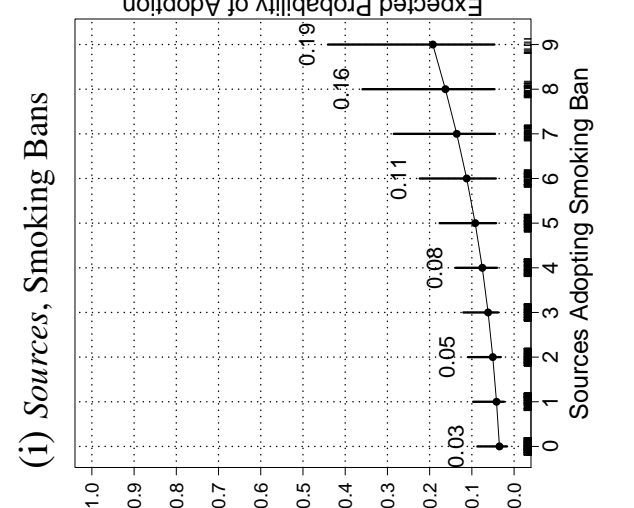

in

电

$\Xi \frac{8}{8}$

. ํ.

范

를

$\stackrel{\square}{\Xi}$

$\stackrel{\oplus}{\Xi}$

$\Xi \dot{\sigma}$

ว

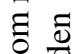

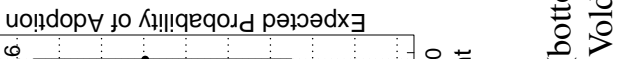

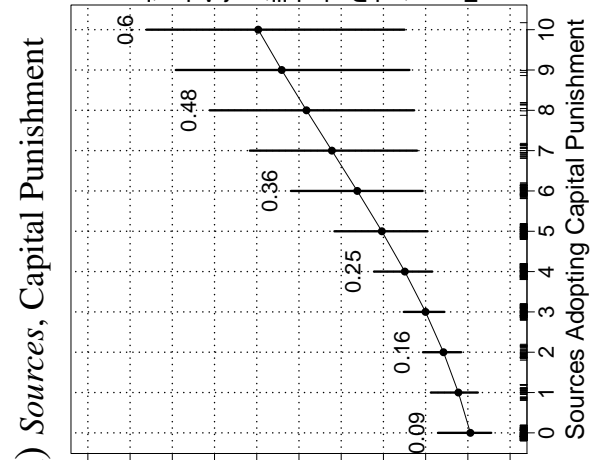

크

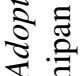

\&

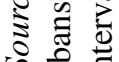

$50 .=$

ส

के

을

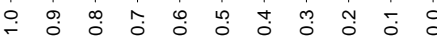

uo!̣dop $\forall$ to Kł!!!qeqodd pəłoədx $\exists$

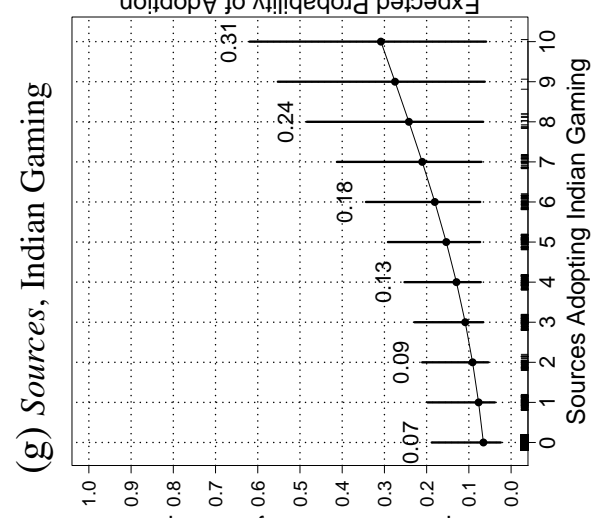

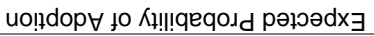

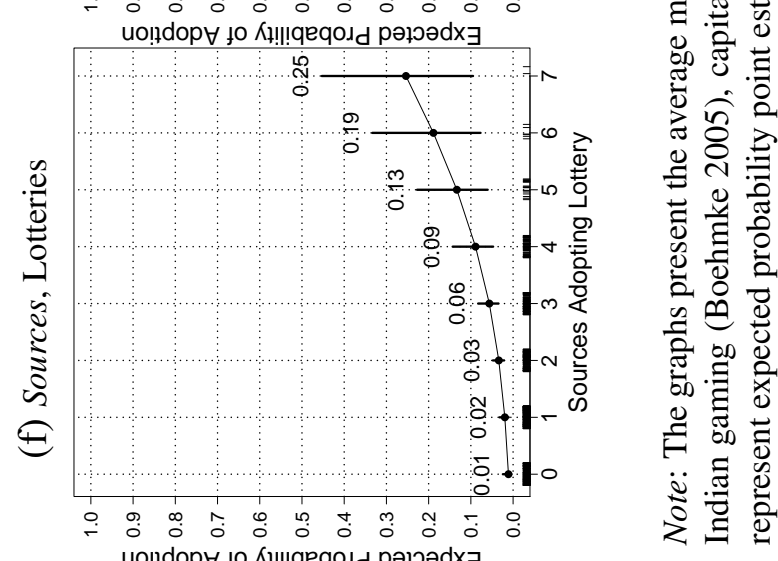

xviii 

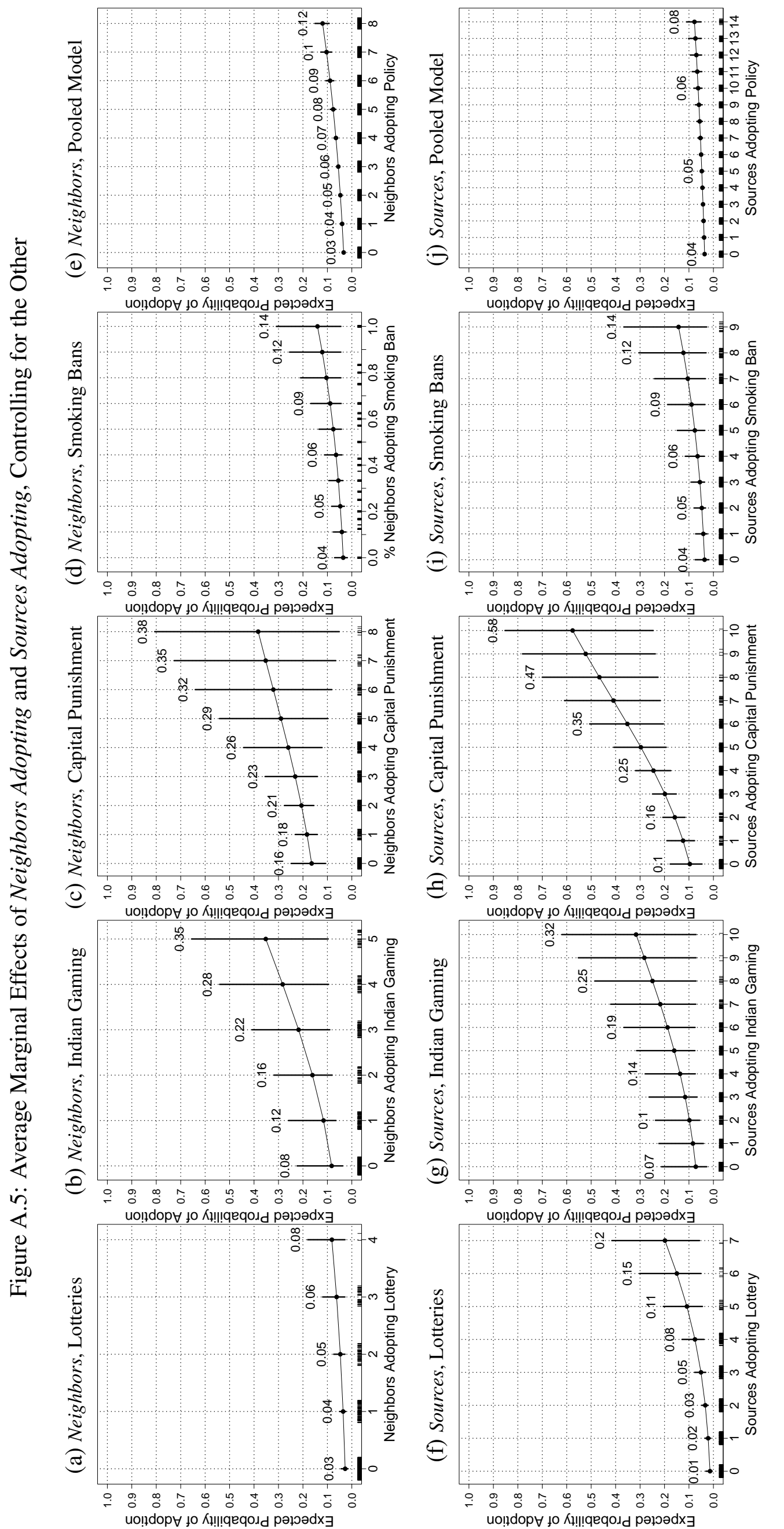

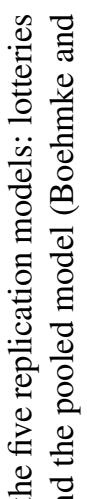

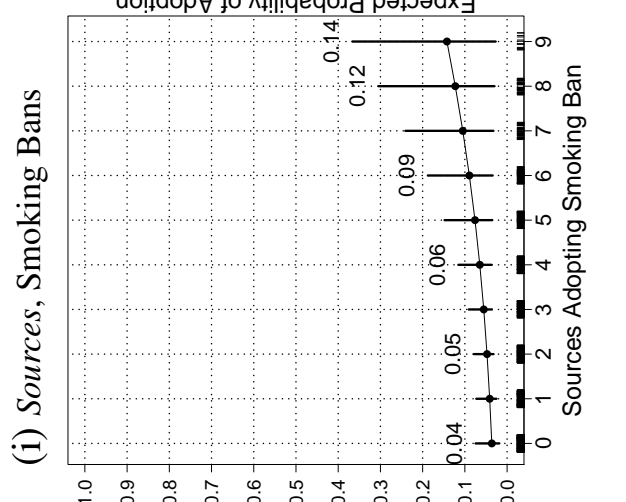

$\Xi \approx$

过

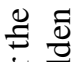

0

$\stackrel{0}{\Xi}$

䒕善

잉

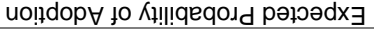

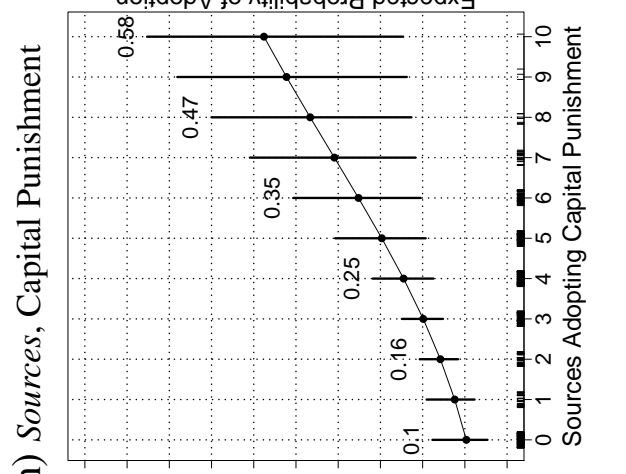

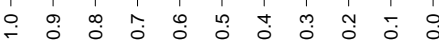

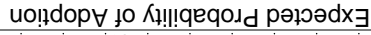

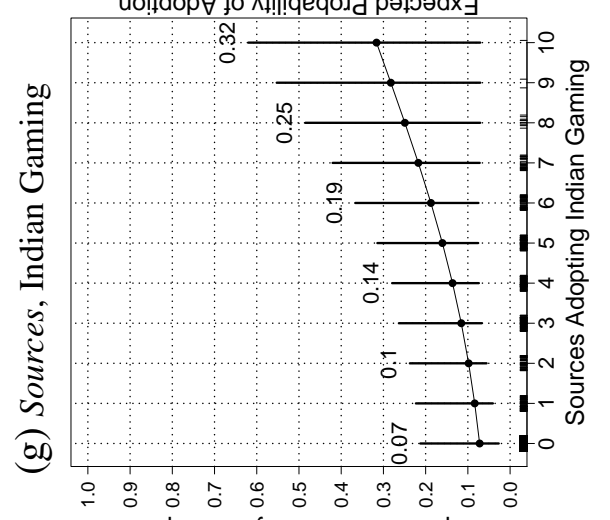

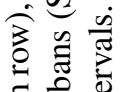

毒

8 :

范吾

$8 \exists$

र

亏ิ

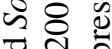

要

उह

응

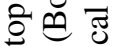

$\infty$ 获

帘言

㞋。

현

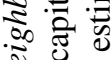

之.

पू

유

总

픙 응

कo 9

ق.

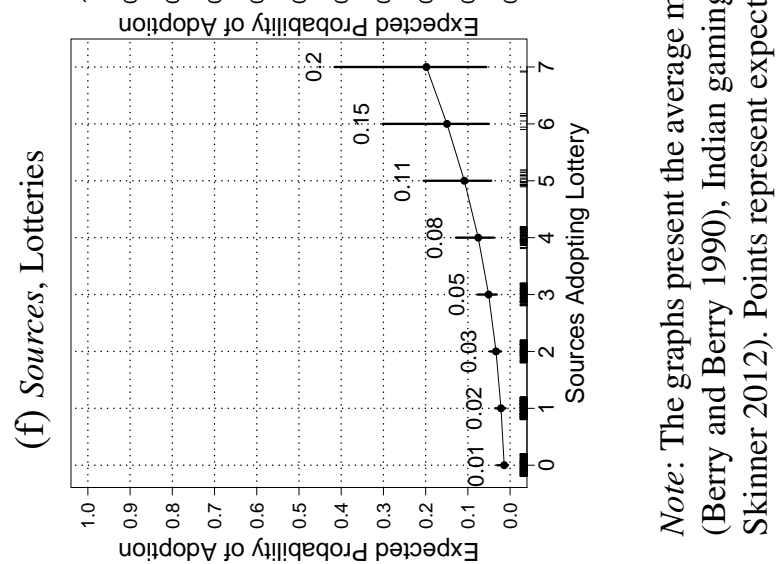


Table A.1: Effect of Diffusion Ties on Emulation Stories, Adjusting for Total State Coverage

\begin{tabular}{rccc}
\hline & Estimate & $2.5 \%$-tile & $97.5 \%$-tile \\
\hline Intercept & -6.712 & -14.863 & 0.292 \\
$\ln (1+$ mean ties $)$ & 0.779 & 0.456 & 1.045 \\
$\ln (1+$ total coverage $)$ & 1.030 & -0.005 & 2.240 \\
\hline $\mathrm{R}^{2}$ & 0.423 & & \\
$N$ & 50 & & \\
\hline
\end{tabular}

Note: OLS Regression coefficients reported with percentile bootstrap confidence intervals constructed with 10,000 resampling iterations. The dependent variable is $\ln (1+$ emulation stories $)$. 
Table A.2: News Outlets Reporting Emulation Stories in LexisNexis

\begin{tabular}{|c|c|c|}
\hline The Atlanta Journal-Constitution & 11 & The Tampa Tribune (Florida) \\
\hline St. Louis Post-Dispatch & 10 & The Vancouver Sun (12 hour delay) \\
\hline The Denver Post & 10 & Whittier Daily News (California) \\
\hline Tampa Bay Times & 9 & Wisconsin State Journal \\
\hline The Philadelphia Inquirer & 9 & American Banker \\
\hline Deseret Morning News (Salt Lake City) & 8 & Clean Air Report \\
\hline Lincoln Journal Star (Nebraska) & 8 & CongressNow \\
\hline Providence Journal & 8 & Daily News (New York) \\
\hline St. Paul Pioneer Press (Minnesota) & 8 & El Paso Times (Texas) \\
\hline Omaha World Herald & 7 & Electric Power Daily \\
\hline Portland Press Herald & 7 & Electric Utility Week \\
\hline San Jose Mercury News (California) & 7 & Environmental Policy Alert \\
\hline Tulsa World (Oklahoma) & 7 & Eureka Times-Standard (California) \\
\hline The Palm Beach Post & 6 & Finance \& Commerce (Minneapolis, MN) \\
\hline The Record (Bergen County, NJ) & 6 & Global Power Report \\
\hline Topeka Capital-Journal & 6 & guardian.co.uk \\
\hline Pittsburgh Post-Gazette & 5 & Idaho Falls Post Register \\
\hline Contra Costa Times & 4 & Inside EPA Weekly Report \\
\hline South Bend Tribune & 4 & Investor's Business Daily \\
\hline The Charleston Gazette & 4 & Legal News Line \\
\hline The Salt Lake Tribune & 4 & Long Island Business News (Long Island, NY) \\
\hline Discover America's Story & 3 & Maryland Gazette \\
\hline Herald News (Passaic County, NJ) & 3 & Michigan Lawyers Weekly \\
\hline News-Journal (Daytona Beach, Florida) & 3 & Missouri Lawyers Media \\
\hline Richmond Times Dispatch & 3 & Monterey County Herald (CA) \\
\hline San Gabriel Valley Tribune (San Gabriel Valley, CA) & 3 & Nanaimo Daily News (12 hour delay) \\
\hline Sarasota Herald-Tribune & 3 & National Post (12 hour delay) \\
\hline The Austin American-Statesman & 3 & North Carolina Lawyers Weekly \\
\hline The Bond Buyer & 3 & North Jersey Community Newspapers \\
\hline The Capital (Annapolis, MD) & 3 & Ottawa Citizen (12 hour delay) \\
\hline The Toronto Star & 3 & Pasadena Star-News (California) \\
\hline The Union Leader & 3 & Pittsburgh Tribune Review \\
\hline Bangor Daily News (Maine) & 2 & Platts Megawatt Daily \\
\hline Brattleboro Reformer (Vermont) & 2 & Public Opinion (Chambersburg, Pennsylvania) \\
\hline Charleston Daily Mail & 2 & Ruidoso News (New Mexico) \\
\hline Chicago Daily Herald & 2 & San Bernardino Sun (California) \\
\hline Crain's Detroit Business & 2 & San Mateo County Times (San Mateo, CA) \\
\hline Digital Archives & 2 & Star Tribune (Minneapolis MN) \\
\hline Dolan Publications & 2 & Telegraph Herald (Dubuque, IA) \\
\hline Information Bank Abstracts & 2 & The Baltimore Sun (most recent 6 months) \\
\hline Inland Valley Daily Bulletin (Ontario, CA) & 2 & The Buffalo News (New York) \\
\hline Inside Bay Area (California) & 2 & The Calgary Herald (12 hour delay) \\
\hline Journal Record Legislative Report (Oklahoma City, OK) & 2 & The Capital Times (Madison, Wisconsin) \\
\hline Legal Monitor Worldwide & 2 & The Columbian (Vancouver, WA) \\
\hline McClatchy Tribune News non-restricted & 2 & The Decatur Daily (Alabama) \\
\hline Metropolitan News Enterprise & 2 & The Gazette (12 hour delay) \\
\hline Star-News (Wilmington, NC) & 2 & The Globe and Mail (Canada) \\
\hline Telegram \& Gazette (Massachusetts) & 2 & The Hamilton Spectator (Ontario, Canada) \\
\hline The Berkshire Eagle (Pittsfield, Massachusetts) & 2 & The Hill \\
\hline The Bismarck Tribune & 2 & The Indianapolis Business Journal \\
\hline The Daily News of Los Angeles & 2 & The New York Post \\
\hline The Daily Oklahoman (Oklahoma City, OK) & 2 & The Pantagraph \\
\hline The Daily Record (Baltimore, MD) & 2 & The Patriot Ledger \\
\hline The Florida Times Union & 2 & The Spokesman-Review \\
\hline The Journal Record (Oklahoma City, OK) & 2 & The Straits Times (Singapore) \\
\hline The Ledger (Lakeland) & 2 & The York Dispatch (York, PA) \\
\hline The Santa Fe New Mexican & 2 & University Wire \\
\hline The State Journal-Register (Springfield, IL) & 2 & Vallejo Times-Herald (California) \\
\hline
\end{tabular}

Note: Entries report news outlets and number of emulation stories identified in LexisNexis. 
Table A.3: Estimates and Model Fit Statistics for Neighbors Adopting and Sources Adopting in the Replication Models

\begin{tabular}{|c|c|c|c|}
\hline & $\begin{array}{l}\text { Only Neighbors } \\
\text { (Original Model) }\end{array}$ & $\begin{array}{l}\text { Only } \\
\text { Sources }\end{array}$ & $\begin{array}{l}\text { Neighbors and } \\
\text { Sources }\end{array}$ \\
\hline \multicolumn{4}{|c|}{ Berry and Berry (1990): Lotteries (Probit, $\mathrm{N}=857$ ) } \\
\hline Neighbors Adopting & $\begin{array}{c}0.27^{*} \\
(0.09)\end{array}$ & & $\begin{array}{r}0.16 \\
(0.10)\end{array}$ \\
\hline Sources Adopting & & $\begin{array}{r}0.30^{*} \\
(0.09)\end{array}$ & $\begin{array}{c}0.25^{*} \\
(0.10)\end{array}$ \\
\hline AIC & 195.12 & 189.96 & 189.64 \\
\hline BIC & 233.15 & 227.99 & 232.42 \\
\hline CV \% Correctly Classified & $94 \%$ & $\mathbf{9 5 \%}$ & $95 \%$ \\
\hline \multicolumn{4}{|c|}{ Boehmke (2005): Indian Gaming (Probit, N = 364) } \\
\hline Neighbors Adopting & $\begin{array}{c}0.42^{*} \\
(0.20)\end{array}$ & & $\begin{array}{l}0.42^{*} \\
(0.21)\end{array}$ \\
\hline Sources Adopting & & $\begin{array}{l}0.20^{+} \\
(0.12)\end{array}$ & $\begin{array}{r}0.21 \\
(0.13)\end{array}$ \\
\hline AIC & 144.25 & 144.45 & 143.54 \\
\hline BIC & 241.68 & 237.98 & 244.86 \\
\hline CV \% Correctly Classified & $89 \%$ & $91 \%$ & $90 \%$ \\
\hline \multicolumn{4}{|c|}{ Boehmke (2005): Capital Punishment (Probit, N = 227) } \\
\hline Neighbors Adopting & $\begin{array}{r}0.16 \\
(0.14)\end{array}$ & & $\begin{array}{r}0.14 \\
(0.14)\end{array}$ \\
\hline Sources Adopting & & $\begin{array}{c}0.24^{*} \\
(0.10)\end{array}$ & $\begin{array}{c}0.23^{*} \\
(0.10)\end{array}$ \\
\hline AIC & 204.53 & 199.66 & 200.97 \\
\hline $\mathrm{BIC}$ & 283.31 & 278.43 & 283.17 \\
\hline CV \% Correctly Classified & $75 \%$ & $\mathbf{7 8 \%}$ & $76 \%$ \\
\hline \multicolumn{4}{|c|}{ Shipan and Volden (2006): Restaurant Smoking Bans (Logit, N = 807) } \\
\hline$\%$ Neighbors Adopting & $\begin{array}{l}1.92^{*} \\
(0.86)\end{array}$ & & $\begin{array}{l}1.66^{+} \\
(0.94)\end{array}$ \\
\hline Sources Adopting & & $\begin{array}{c}0.25^{*} \\
(0.12)\end{array}$ & $\begin{array}{r}0.19 \\
(0.14)\end{array}$ \\
\hline AIC & 248.57 & 249.96 & 249.16 \\
\hline $\mathrm{BIC}$ & 328.36 & 329.75 & 333.64 \\
\hline CV \% Correctly Classified & $\mathbf{9 4 \%}$ & $93 \%$ & $94 \%$ \\
\hline \multicolumn{4}{|c|}{ 151-Policy Pooled Model (Logit, N = 62,290) } \\
\hline Neighbors Adopting & $\begin{array}{r}0.22^{*} \\
(0.02)\end{array}$ & & $\begin{array}{c}0.19^{*} \\
(0.02)\end{array}$ \\
\hline Sources Adopting & & $\begin{array}{c}0.13^{*} \\
(0.02)\end{array}$ & $\begin{array}{r}0.06^{*} \\
(0.02)\end{array}$ \\
\hline AIC & 17030.64 & 17089.78 & 17021.47 \\
\hline $\mathrm{BIC}$ & 19263.41 & 19322.55 & 19263.28 \\
\hline CV \% Correctly Classified & $93 \%$ & $93 \%$ & $94 \%$ \\
\hline
\end{tabular}


Table A.4: Estimates and Model Fit Statistics for Neighbors Adopting and Percentage of Sources Adopting in the Replication Models

\begin{tabular}{|c|c|c|c|}
\hline & $\begin{array}{l}\text { Only Neighbors } \\
\text { (Original Model) }\end{array}$ & $\begin{array}{c}\text { Only } \\
\text { Sources }\end{array}$ & $\begin{array}{l}\text { Neighbors and } \\
\text { Sources }\end{array}$ \\
\hline \multicolumn{4}{|c|}{ Berry and Berry (1990): Lotteries (Probit, N = 857) } \\
\hline Neighbors Adopting & $\begin{array}{c}0.27^{*} \\
(0.09)\end{array}$ & & $\begin{array}{c}0.20^{*} \\
(0.10)\end{array}$ \\
\hline$\%$ Sources Adopting & & $\begin{array}{l}1.57^{*} \\
(0.52)\end{array}$ & $\begin{array}{r}1.30^{*} \\
(0.56)\end{array}$ \\
\hline AIC & 195.12 & 193.22 & 191.41 \\
\hline $\mathrm{BIC}$ & 233.15 & 231.25 & 234.20 \\
\hline CV \% Correctly Classified & $94 \%$ & $95 \%$ & $95 \%$ \\
\hline \multicolumn{4}{|c|}{ Boehmke (2005): Indian Gaming (Probit, N = 364) } \\
\hline Neighbors Adopting & $\begin{array}{c}0.42^{*} \\
(0.20)\end{array}$ & & $\begin{array}{r}0.42^{*} \\
(0.20)\end{array}$ \\
\hline$\%$ Sources Adopting & & $\begin{array}{r}1.10 \\
(0.94)\end{array}$ & $\begin{array}{r}1.04 \\
(0.94)\end{array}$ \\
\hline AIC & 144.25 & 145.92 & 145.11 \\
\hline BIC & 241.68 & 239.45 & 246.44 \\
\hline CV \% Correctly Classified & $89 \%$ & $91 \%$ & $89 \%$ \\
\hline \multicolumn{4}{|c|}{ Boehmke (2005): Capital Punishment (Probit, N = 227) } \\
\hline Neighbors Adopting & $\begin{array}{r}0.16 \\
(0.14)\end{array}$ & & $\begin{array}{r}0.15 \\
(0.14)\end{array}$ \\
\hline$\%$ Sources Adopting & & $\begin{array}{l}2.15^{*} \\
(0.77)\end{array}$ & $\begin{array}{l}2.13^{*} \\
(0.77)\end{array}$ \\
\hline AIC & 204.53 & 197.84 & 198.81 \\
\hline BIC & 283.31 & 276.62 & 281.01 \\
\hline CV \% Correctly Classified & $75 \%$ & $76 \%$ & $76 \%$ \\
\hline \multicolumn{4}{|c|}{ Shipan and Volden (2006): Restaurant Smoking Bans (Logit, N = 807) } \\
\hline$\%$ Neighbors Adopting & $\begin{array}{r}1.92^{*} \\
(0.86)\end{array}$ & & $\begin{array}{r}1.73 \\
(0.97)\end{array}$ \\
\hline$\%$ Sources Adopting & & $\begin{array}{r}1.04 \\
(0.85)\end{array}$ & $\begin{array}{r}0.59 \\
(0.93)\end{array}$ \\
\hline AIC & 248.57 & 250.89 & 249.87 \\
\hline $\mathrm{BIC}$ & 328.36 & 330.50 & 334.17 \\
\hline CV \% Correctly Classified & $94 \%$ & $93 \%$ & $94 \%$ \\
\hline \multicolumn{4}{|c|}{ 151-Policy Pooled Model (Logit, N = 62,290) } \\
\hline Neighbors Adopting & $\begin{array}{l}0.22^{*} \\
(0.02)\end{array}$ & & $\begin{array}{r}0.18^{*} \\
(0.02)\end{array}$ \\
\hline$\%$ Sources Adopting & & $\begin{array}{l}0.91^{*} \\
(0.12)\end{array}$ & $\begin{array}{c}0.54^{*} \\
(0.13)\end{array}$ \\
\hline AIC & 17030.64 & 17073.94 & 17011.82 \\
\hline BIC & 19263.41 & 19306.71 & 19253.63 \\
\hline CV \% Correctly Classified & $93 \%$ & $93 \%$ & $94 \%$ \\
\hline
\end{tabular}

Note: Cell entries report coefficient estimates and standard errors (in parentheses) for Neighbors Adopting and \% Sources Adopting and AIC, BIC, and cross-validated percent correctly classified values in three specifications of the replication models. All other variables from the original models are included, but those estimates are not shown to conserve space. Numbers in bold identify the best-fitting model for each fit statistic. ${ }^{*} p<0.05{ }^{+} p<0.10$. 
Table A.5: Fixed Effects Logit Models of State Policy Diffusion Ties

\begin{tabular}{|c|c|c|c|c|}
\hline & Coef. & S.E. & Coef. & S.E. \\
\hline \multicolumn{5}{|l|}{ Follower State Characteristics: } \\
\hline Citizen Ideology & & & $-0.014^{*}$ & $(0.002)$ \\
\hline Legislative Professionalism & & & -0.397 & $(0.244)$ \\
\hline Minority Diversity & & & $0.790^{+}$ & $(0.245)$ \\
\hline Per Capita Income & & & $0.699 *$ & $(0.097)$ \\
\hline Population & & & $0.184^{+}$ & $(0.012)$ \\
\hline Unified Democratic Government & & & 0.011 & $(0.035)$ \\
\hline Unified Republican Government & & & -0.029 & $(0.041)$ \\
\hline \multicolumn{5}{|l|}{ Potential Source Characteristics: } \\
\hline Citizen Ideology & & & $-0.007^{*}$ & $(0.002)$ \\
\hline Legislative Professionalism & & & -0.133 & $(0.250)$ \\
\hline Minority Diversity & & & -0.147 & $(0.246)$ \\
\hline Per Capita Income & & & -0.037 & $(0.093)$ \\
\hline Population & & & $0.073^{*}$ & $(0.014)$ \\
\hline Unified Democratic Government & & & -0.038 & $(0.035)$ \\
\hline Unified Republican Government & & & -0.075 & $(0.040)$ \\
\hline \multicolumn{5}{|l|}{ Relative Follower/Source Characteristics: } \\
\hline Contiguity & $0.149^{+}$ & $(0.039)$ & 0.037 & $(0.040)$ \\
\hline Distance Between Capitals & $-0.238^{*}$ & $(0.021)$ & $-0.208^{+}$ & $(0.021)$ \\
\hline Citizen Ideology (Absolute Difference) & & & $-0.009^{*}$ & $(0.001)$ \\
\hline Legislative Professionalism (Absolute Difference) & & & $0.282^{+}$ & $(0.141)$ \\
\hline Minority Diversity (Absolute Difference) & & & -0.119 & $(0.107)$ \\
\hline Per Capita Income (Absolute Difference) & & & $-0.428^{*}$ & $(0.049)$ \\
\hline Population (Absolute Difference) & & & $-0.035^{+}$ & $(0.004)$ \\
\hline Unified Democratic (Product) & & & $0.123^{+}$ & $(0.046)$ \\
\hline Unified Republican (Product) & & & -0.078 & $(0.083)$ \\
\hline Intercept & $-3.611^{*}$ & $(0.202)$ & $-3.133^{*}$ & $(0.384)$ \\
\hline $\bar{N}$ & \multicolumn{2}{|c|}{94,080} & \multicolumn{2}{|c|}{94,080} \\
\hline AIC & \multicolumn{2}{|c|}{62,821} & \multicolumn{2}{|c|}{62,048} \\
\hline
\end{tabular}

Note: Observations are dyadic. The dependent variable indicates whether potential source state is in fact a source for a follower state. We use the network with 300 edges over 35 years of policy adoptions. indicates statistical significance at the 0.05 level (two-tailed) according to just the parametric $p$-values from the multilevel logit. * indicates statistical significance at the 0.05 level according to the QAP $p$-values and the parametric $p$-values. QAP $p$-values derived from 1000 network permutations. 